\title{
INVESTIGATING THE RELATIONSHIP BETWEEN OPERATIONS EFFICIENCY AND CUSTOMER SATISFACTION
}

\author{
A Thesis \\ presented to \\ the Faculty of California Polytechnic State University, \\ San Luis Obispo
}

\author{
In Partial Fulfillment \\ of the Requirements for the Degree \\ Master of Science in Industrial Engineering
}

by

Monica J. Reinwald

December 2013 
(C) 2013

Monica J. Reinwald

ALL RIGHTS RESERVED 


\section{COMMITTEE MEMBERSHIP}

TITLE:

Investigating the Relationship between Operations

Efficiency and Customer Satisfaction

AUTHOR:

Monica J. Reinwald

DATE SUBMITTED:

December 2013

COMMITTEE CHAIR:

Dr. Lizabeth Schlemer, Professor,

Industrial and Manufacturing Engineering

COMMITTEE MEMBER: Dr. Roya Javadpour, Professor, Industrial and Manufacturing Engineering

COMMITTEE MEMBER: Dr. Reza Pouraghabagher, Professor, Industrial and Manufacturing Engineering 


\begin{abstract}
Investigating the Relationship between Operations Efficiency and Customer Satisfaction
\end{abstract}

\title{
Monica J. Reinwald
}

The importance of efficiency in the service industry has continued to grow with the increase of services in today's society. As a result, services must maintain efficient operations in order to achieve positive customer satisfaction and retain their customers. The fear of receiving negative customer satisfaction often results in a firm owner's reluctance to improve efficiency operations because he or she believes it will hurt sales. This thesis provides a background on restaurant operations efficiency and customer satisfaction and discusses a case study used to explore the effect of efficiency on customer satisfaction. The case study consisted of a time study and customer survey based on a scale called SERVQUAL, which is used as a measure of service quality. The wait times collected during the time study were correlated with the customer survey responses in order to determine strong correlations. Four of the five strong correlations related to the tangibles dimension of service quality, which corresponds to the appearance of the restaurant facilities, equipment, and staff. Due to the determined importance of the tangibles dimension, it can be used as a measure for customer satisfaction. A polynomial regression model was then generated based on the strong correlations. The model indicates that shorter 
order wait times do not negatively affect customer satisfaction much, but rather, longer order wait times more strongly affect customer satisfaction. Therefore based on the regression model, restaurant owners and managers should focus on reducing the customer order wait time because reducing this time results in higher levels of customer satisfaction. Additionally, these results show that restaurants can choose to increase revenue by improving their efficiency without fear of hurting their customer satisfaction. 


\section{TABLE OF CONTENTS}

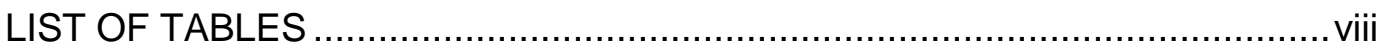

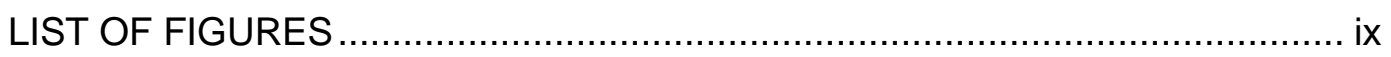

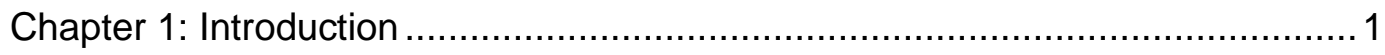

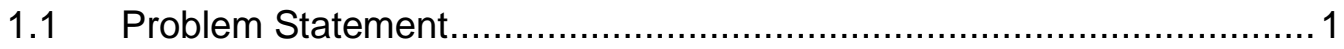

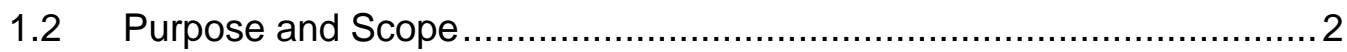

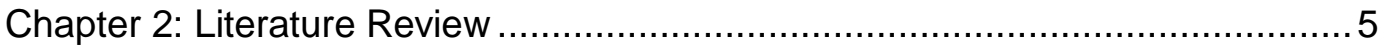

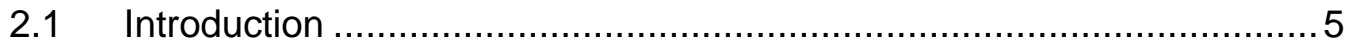

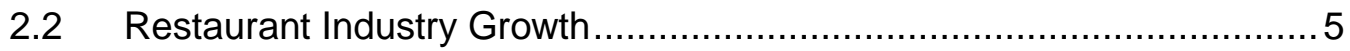

2.3 Restaurant Categorization ......................................................... 6

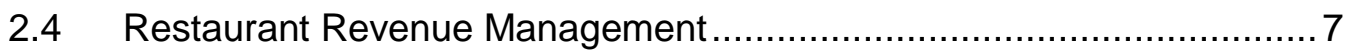

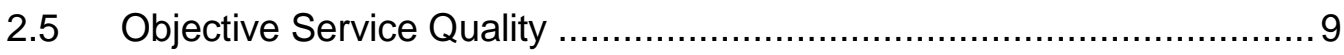

2.6 Perceived Service Quality ................................................... 12

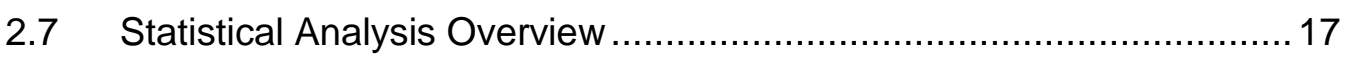

2.8 Regression Analysis versus ANOVA ......................................... 19

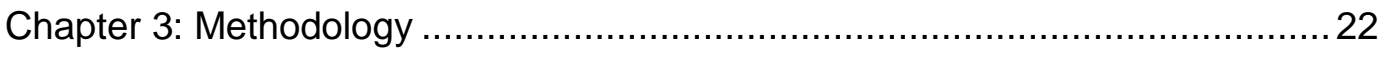

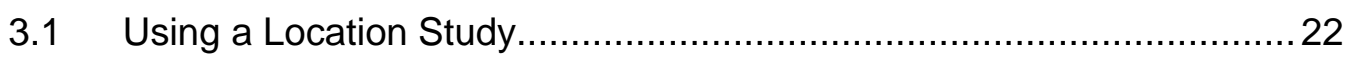

3.2 Measuring Operations Efficiency ............................................ 22

3.3 Measuring Customer Satisfaction ............................................. 22

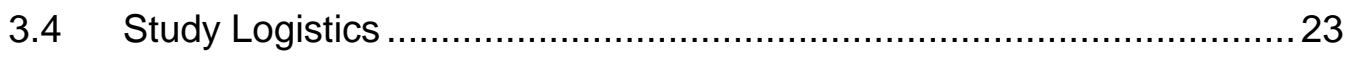

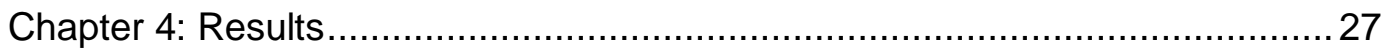

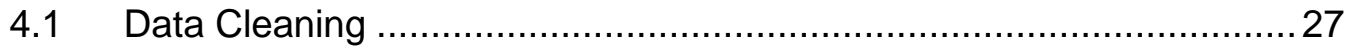

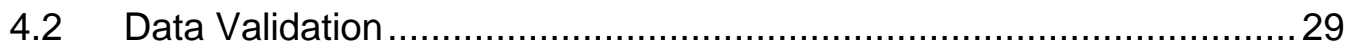




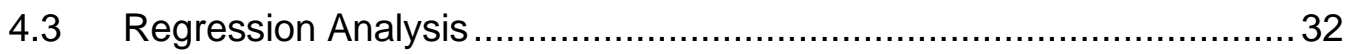

4.4 Customer Expectations versus Perceptions .................................. 35

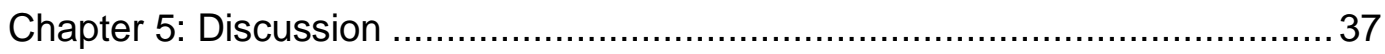

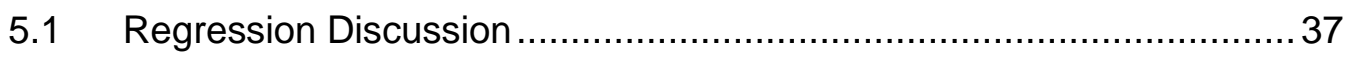

5.2 Customer Expectations versus Perceptions Discussion ......................39

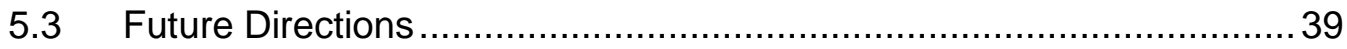

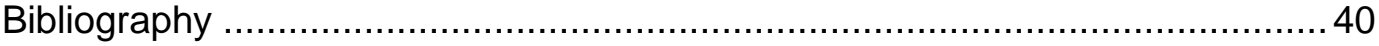

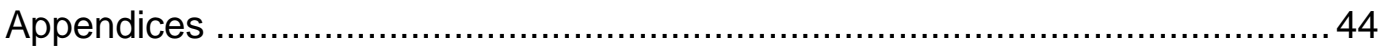

Appendix A: Supporting Tables and Figures ........................................ 44

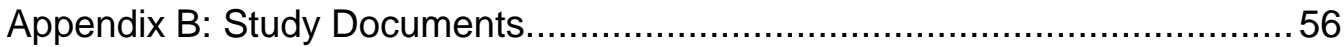




\section{LIST OF TABLES}

Table 1: All Study Data Descriptive Statistics ............................................ 30

Table 2. Two-Sample T-Test between Study Days P-Values........................... 32

Table 3: Significant Correlation Coefficient Summary ................................... 33

Table 4. Customer Expectation vs. Perceptions Two-Sample T-Test P-Values . 36 


\section{LIST OF FIGURES}

Figure 1. Growth of restaurant industry since 1955 (National Restaurant

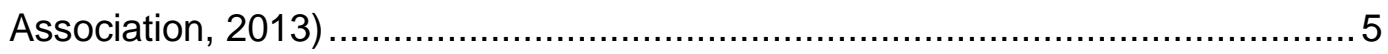

Figure 2. Layout of Restaurant Study Location ........................................... 25

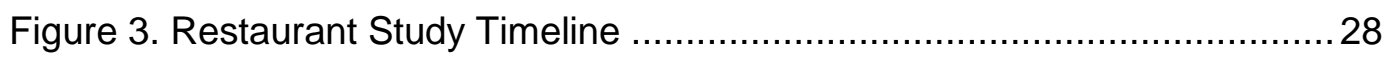

Figure 4. Polynomial Regression Curve, Tangibles vs. Order Wait Time ........... 35 


\section{Chapter 1: Introduction}

\subsection{Problem Statement}

The importance of efficiency in the service industry has continued to grow with the increase of services in today's society. People rely more and more on a diverse range of services to make their lives easier. As the reliance on services has increased, the competition between service firms has escalated. As a result, services must maintain efficient operations in order to achieve positive customer satisfaction and retain their customers.

Service industries rely on positive customer satisfaction for survival. This occurs by providing quality services efficiently and at an acceptable cost to the customer. Due to the variable nature of service industries, efficient operations may be achieved in a multitude of ways. Additionally, certain efficiency levels may result in negative customer satisfaction. For example, customers may not enjoy a streamlined meal in a restaurant if they do not have enough time to enjoy each course before the next one arrives. However, customers may also react negatively to a meal with long wait times between each course because they feel the meal took too much of their time. Most restaurant owners will probably agree that maximizing efficiency, measured by speed of service, will not necessarily maximize customer satisfaction. 
The fear of receiving negative customer satisfaction often results in a firm owner's reluctance to improve efficiency operations because he or she believes it will hurt sales. If customers appear satisfied with the current efficiency level, firm owners may decide not to change any aspect of their business that affects speed of service. This unknown relationship between efficiency and customer satisfaction may cause firms to operate inefficiently and may result in wasted time and money. Balancing a firm's operations and customer satisfaction becomes a delicate balancing game that can determine a firm's success or failure. Minimal research has been conducted to date that relates improving operations efficiency and its relationship to improving customer satisfaction. As a result, the effect of efficiency on customer satisfaction is not known. This thesis intends to bridge that gap.

\subsection{Purpose and Scope}

The service sector contains a wide range of services in a variety of formats. Services such as banking, vehicle repair and maintenance, and food services are only a sample of the services available in today's society. In addition to the variety of service industries, many services offer a range of service formats. These can include physical locations, such as a restaurant, telephone support for services such as utilities, and online support for services such as banking. The multitude of options provides a challenge for firms in the service sector because they must satisfy customers under a diverse set of circumstances. 
Each service format offers a unique set of challenges to firm managers in a particular industry, and concerns in one industry may not pertain to another industry. For example, customer security may be a priority for banks, while restaurants may want to focus on food quality. This creates a challenge for anyone looking to relate operations efficiency with customer satisfaction due to the potential for an extremely large number of variables that arise from the variety of service industries in today's society. Nevertheless, management in most industries judge operations based on the speed of service as the measure of efficiency. This holds true for service operations. However, because services are directly experienced by customers, an efficient operation may not translate into a good customer experience.

As a basis for determining if there is a definable relationship between operations efficiency and customer satisfaction, this thesis focuses specifically on restaurants classified as casual dining by the National Restaurant Association. By focusing on a single segment of one service industry, the potential variability between industries can be eliminated while determining the possibility of defining a relationship between operations efficiency and customer satisfaction. Once the potential relationship is defined, it can be reevaluated, modified, and applied to other service industries.

This thesis begins by providing background information regarding restaurant operations efficiency and customer satisfaction. A description of the experiment methodology used to approach this topic follows. Following the methodology, the 
data analysis and results are presented and discussed. Final comments and future recommendations conclude the report. 


\section{Chapter 2: Literature Review}

\section{$2.1 \quad$ Introduction}

This section provides background on topics relevant to this thesis. It begins with an introduction to the restaurant industry and statistics showing its growth and importance in today's economy, followed by a discussion on current restaurant revenue management techniques. An explanation of both objective and perceived service quality follows, with an introduction to inferential statistics concluding this section. The first half of this section displays the importance of this paper's topic, while the second half presents topics used in the analysis and conclusion portions of this paper.

\subsection{Restaurant Industry Growth}

The restaurant industry within the U.S. has continued to grow over the last several decades. Restaurant industry sales are projected to equal $4 \%$ of the U.S. gross domestic product with a total of $\$ 660.5$ billion in 2013 (National Restaurant Association, 2013). Figure 1 below shows the growth of the restaurant industry over the last half a century.

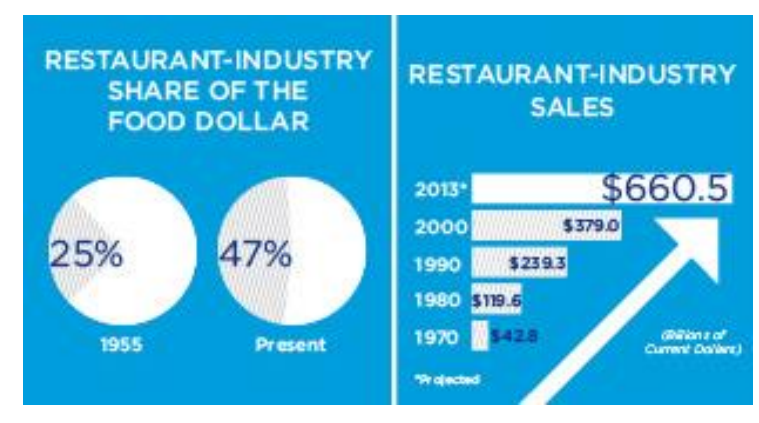

Figure 1. Growth of restaurant industry since 1955 (National Restaurant Association, 2013) 
Restaurant industry job growth outpaced the overall economy for 13 consecutive years, from 2000 to 2012 , and is expected to employ nearly $10 \%$ of the U.S. workforce with 13.1 million people in 2013. As the restaurant industry continues to grow, it becomes vital for restaurants to offer high quality dining experiences to their customers while maintaining efficient operations.

\subsection{Restaurant Categorization}

There are two main types of restaurants in the industry: fast food and full service. Fast food restaurants "primarily engage in the retail of prepared food and drinks for on-premise or immediate consumption" (Research and Markets: 2013 U.S. Fast Food Restaurants Industry - Industry \& Market Report, 2012, p. 1). A full service restaurant offers a wide selection of foods and beverages and table service (WebFinance, Inc., 2013). The casual dining and family dining sectors both reside in the full service industry. Brent Shearer loosely defines a casual dining restaurant as "a restaurant where you sit down, place an order, and your food is brought to you" (Shearer, 2000, p. 40). The National Restaurant Association defines the casual dining sector as one that contains check sizes ranging from $\$ 8$ to $\$ 22$. Checks below $\$ 8$ fall into the family-style category. Additionally the presence of alcohol separates casual dining from the family dining category (Shearer, 2000). 


\subsection{Restaurant Revenue Management}

Restaurant revenue management is a technique where restaurant owners strategically set prices and influence customer meal duration to try to achieve optimum revenue per seat hour. In essence, "Restaurant revenue management can be defined as selling the right seat to the right customer at the right prices for the right duration" (Kimes, Wirtz, \& Noone, 2002, p. 221). Three operational efficiency measures commonly used in restaurant revenue management include meal duration, average check, and revenue per available seat-hour.

Meal duration, one of the most important operational efficiency metrics for restaurant performance, is the amount of time from the initial seating of a party until the party departs and the table is prepped for the arrival of another party (Thompson \& Kwortnik, 2008). Also known as table turn time, meal duration is comprised of wait time, service time, and consumption time, and varies by customer. Due to its impact on customer satisfaction, many restaurants hesitate to broach this topic with customers. Therefore the struggle to develop internal methods of managing meal duration is difficult and often blocks the successful implementation of revenue management. This is a good example of the tension between efficiency and customer satisfaction. Streamlining the service-delivery process, changing reservation policies, redesigning menus, and pacing service processes are methods of indirectly affecting meal duration. The resulting decreases in meal duration provide an opportunity for restaurants to increase potential revenue. However, careful attention must be paid to the customers' opinions of their dining experience, as both short and lengthy meal durations can 
negatively affect a customer's perception of their dining experience. A study conducted through the Cornell University School of Hotel Administration calculated an overall expected dining time of 60.2 minutes at casual dining restaurants. This dining time varies by nationality of the customer, with an expected dining time of 57.2 minutes for Asians, 59.0 minutes for North Americans, and 77.3 minutes for Europeans (Kimes, Wirtz, \& Noone, 2002).

Another efficiency metric used in restaurant revenue management is revenue per available seat-hour. Known as the acronym RevPASH, revenue per available seat hour was developed by Sheryl Kimes and uses information from seat use and the average check to "provide a measure of the flow of revenue through the system and to indicate how effectively a restaurant is using its productive capacity" (Kimes, 1999, p. 17). It provides a better indicator of the revenue generating performance of a restaurant than evaluating check averages and the food- and labor-cost alone. High check averages cannot evaluate restaurant performance without percentage of capacity use. For example, a high check may be detrimental to the restaurant during times of high demand because the customers may have lingered over their meal while other parties wait for a table. Similarly, focusing on price margins may cause an overemphasis on minimizing costs to the point of losing revenue from disgruntled customers. RevPASH indicates "the rate at which revenue is generated and captures the trade-off between average check and facility use" (Kimes, 1999, p. 19). It is calculated by dividing revenue (or profit) for the desired time period, such as hour, day, or month, by the number of seat-hours available during that interval. For example, 
assume a 100 -seat restaurant makes $\$ 1500$ between 5:00 pm and 6:00 pm on a Friday evening. The RevPASH during this hour is calculated as follows:

$$
\frac{\$ 1500}{100 \text { seats } x 1 \text { hour }}=\$ 15 \text { per available seat hour }
$$

If the same 100 -seat restaurant made $\$ 5000$ between 4:00 pm and 8:00 pm, the RevPASH over this 4-hour period would be:

$$
\frac{\$ 5000}{100 \text { seats } x 4 \text { hours }}=\$ 12.50 \text { per available seat hour }
$$

This calculated value can assist restaurant managers with determining whether to attempt to influence customer behavior during a particular time period. For example, restaurant managers may want to focus on decreasing meal duration when the calculated RevPASH value is high; this is because a high RevPASH value indicates that the restaurant is more fully utilizing its available seating than during a period when a low RevPASH value is calculated, indicating a higher customer demand for seating. Alternately, when a restaurant experiences a period with a low RevPASH value, restaurant managers should consider trying to attract more customers or increasing the average check size of current customers.

\subsection{Objective Service Quality}

Quality may be defined in several ways. A traditional definition for quality states that quality means fitness for use; in other words, the level the product or service meets the requirements of those who use them (Montgomery, 2009). Fitness for 
use includes two aspects: quality of design and quality of conformance. Quality of design signifies the grade or level of quality, while quality of conformance represents how well the product or service conforms to the specifications required by the design.

The concept of quality contains eight dimensions upon which the quality of a product or service may be measured (Montgomery, 2009). The first is performance, which determines if the product or service does the intended job. The second is reliability, which measures how often a product or service fails. The third, durability, measures the lifespan of the product or service. The fourth, serviceability, determines how easily a product or service may be repaired or corrected. The fifth dimension of quality is aesthetics, which measures sensory factors such as a product's packaging style or a service location's cleanliness. The sixth dimension of quality measures the features of a product or service. The seventh is perceived quality, which is described in detail in the next section. The final dimension of quality is conformance to standards, which determines if the product or service matches the designer's intentions.

The importance of quality has continued to grow over the last several decades. Companies have realized the importance of quality and have worked to improve their quality control methods. W. Edwards Deming developed a 14-point framework summarizing his philosophy of quality and serves as a guideline for management desiring to improve quality at their company. The points support 
Deming's belief that the responsibility for quality rests with management. The 14 points include (Montgomery, 2009):

1. Create a constancy of purpose focused on improvement of products and services.

2. Adopt a new philosophy that recognizes we are in a different economic era.

3. Do not rely on mass inspection to "control" quality.

4. Do not award business to suppliers on the basis of price alone, but also consider quality.

5. Focus on continuous improvement.

6. Practice modern training methods and invest in on-the-job training for all employees.

7. Improve leadership, and practice modern supervision methods.

8. Drive out fear.

9. Break down the barriers between functional areas of the business.

10. Eliminate targets, slogans, and numerical goals for the workforce.

11. Eliminate numerical quotas and work standards.

12. Remove the barriers that discourage employees from doing their jobs.

13. Institute an ongoing program of education for all employees.

14. Create a structure in top management that will vigorously advocate the first 13 points.

The principles discussed by Deming can be used in any industry. Although product quality is more common in quality discussion in the manufacturing 
environment, quality is also vital to the service industry. Within the service industry, quality is often split into two categories: objective quality and perceived quality. Objective quality follows the general quality definition provided above. Perceived quality, the more subjective quality measure of the two, is discussed in depth in the next section. Within service industries, objective quality often measures customer wait times, such as their queue time or service time. Within the restaurant industry specifically, additional objective quality measures relate to the served food, such as food temperature.

\subsection{Perceived Service Quality}

Services contain three unique features that make it difficult to define service quality: intangibility, heterogeneity, and inseparability of production and consumption (Parasuraman, Zeithaml, \& Berry, 1988). Intangibility stems from the fact that services are often based on the performance of tasks rather than the production of an object. This makes it difficult to set precise manufacturing specifications concerning uniform quality. "Most services cannot be counted, measured, inventoried, tested, and verified in advance of sale to assure quality," hindering firms in understanding how consumers perceive and evaluate their service quality (Parasuraman A. , 1985). Services are considered heterogeneous because firm performance varies from producer to producer, from consumer to consumer, and from day to day. This is especially true for services with high labor content. Service personnel behavior consistency may be difficult for a firm to guarantee due to the independent nature of any labor force. Finally, services typically combine production and consumption. This means that service quality is 
not manufactured at a plant and then delivered intact to the consumer; instead, quality occurs during the service and is often directly related to interactions between the consumer and a member of the serving firm. Services with more consumer participation, such as haircuts or doctor's visits, result in even less managerial control over service quality and cause consumer input to become crucial to the quality of the service performed.

In lieu of objective measures, Parasuraman et al. (1988) consider service quality a measure of consumers' perceptions of quality. Perceived quality differs from objective quality; perceived quality is the consumer's judgment regarding a firm's overall superiority or excellence and is a form of attitude resulting from comparing expectations with performance perceptions. Objective quality considers an objective aspect or feature of a product or event.

According to Oliver (1981), perceived quality differs from satisfaction. Perceived quality is a general attitude relating to the superiority of a service as a whole; satisfaction relates to a specific transaction. Oliver (1981) differentiates general attitude from the transaction-specific nature of satisfaction as follows:

Attitude is the consumer's relatively enduring affective orientation for a product, store, or process (e.g. customer service) while satisfaction is the emotional reaction following a disconfirmation experience which acts on the base attitude level and is consumption-specific. Attitude is therefore 
measured in terms more general to product or store and is less situationally oriented. (p. 42)

Perceived quality and satisfaction are related because perceptions of service quality result from incidents of satisfaction over time. "Satisfaction soon decays into one's overall attitude toward purchasing products" (Oliver, 1981).

Parasuraman et al. (1988) concludes that service quality perceived by consumers results from a comparison between what they feel firms should offer and their perceptions of the firms' actual performance. The degree and direction of the discrepancy between consumers' perceptions and expectations defines perceived service quality.

In 1988, Parasuraman et al. developed a multi-item scale called SERVQUAL that could be used to measure consumer perceptions of service quality. The scale measures perceived quality across five dimensions of service quality. These dimensions include: tangibles, which consists of physical facilities, equipment, and appearance of personnel; reliability, which consists of a firm's ability to perform the promised service dependably and accurately; responsiveness, which is a firm's willingness to help customers and provide prompt service; assurance, which is the knowledge and courtesy of employees and their ability to inspire trust and confidence; and empathy, which consists of the caring, individualized attention the firm provides its customers. The scale contains 22 statements regarding a customer's expectations for any firm in a service industry and 
another 22 statements relating to a customer's perceptions of a specific firm within a service industry. For example, the 22 expectation statements may relate to the banking industry in general, with the 22 perception statements asking about a specific bank. Survey participants use a 7-point Likert scale to state their agreement or disagreement with each statement. The SERVQUAL scale consists of both positive and negative statements in order to minimize question phrasing biases. Potential applications of SERVQUAL include assessing areas to focus on to improve service, tracking service quality trends and performance of stores within a chain, and determining the relative importance of the five dimensions of service quality in influencing customers' overall perceptions of quality.

The most recent investigation of the validity of the SERVQUAL scale was conducted in 2007 by Carrillat et al. The study compared the SERVQUAL scale and a competing service quality scale called SERVPERF developed in 1992 by J. Joseph Cronin and Steven A. Taylor. The study concluded that both scales are equally valid predictors of service quality (Carrillat, Jaramillo, \& Mulki, 2007). Additionally, the SERVQUAL scale has been reference over 2,000 times, while the SERVPERF scale has been reference just over 1,000 times.

There are many aspects of a restaurant that may affect a customer's opinion of service quality. One such aspect is the availability of reservations. Restaurants use reservations to assist with managing their variable demand. Reservations help smooth demand, optimize capacity, and minimize queues, all of which may detract from the customer experience (Thompson \& Kwortnik, 2008). A study 
conducted in 2008 examined whether restaurant reservations should be locked to specific tables at the time the reservation is made or whether reservations should be pooled and assigned to tables in real time. The first method is known as locking; the second is known as pooling. The study found that $42.3 \%$ of the 425 acceptable survey responders currently assign reservations to a specific table by party size when the reservation is made; $39.2 \%$ assign reservations to a specific table by party size at the beginning of the meal period. Both methods are considered locking reservations. The study concluded that "pooling restaurant reservations generally is a more efficient service process than locking reservations to specific tables" (Thompson \& Kwortnik, 2008). There are two considerations of the study results presented by the authors: first, because pooling reservations does not affect table turn times, it will at worst yield the same efficiency as locking reservations; second, pooling reservations is more effective in situations with higher customer service levels, larger restaurants, late patrons on average, and larger variations in arrival times.

Another aspect of restaurants that may affect a customer's opinion of service quality is the physical layout of the restaurant. A study from 2004 examined whether table type or configuration affected meal duration or average check. The study suggests that seats that offer greater privacy are preferred by customers. Booths generated the highest spending per minute (SPM), or average check per person per minute; banquet seating (tables located along a permanently fixed bench with chairs directly across the table from the bench) generated the lowest SPM (Kimes \& Robson, 2004). Additionally, tables anchored against a wall, 
window, or other architectural feature did not generate a significantly different SPM from tables that were exposed or unanchored to an architectural feature. The demonstrated relationship between table characteristics and customer behavior can prove useful to both restaurant designers and managers in their efforts to create more profitable operations.

\subsection{Statistical Analysis Overview}

Statistical analysis can provide the basis for choosing actions or making decisions (Johnson, 2011). Statistical ideas suggest a collection process with four crucial steps when information is sought:

1. Set clearly defined goals for the investigation.

2. Make a plan of what data to collect and how to collect it.

3. Apply appropriate statistical methods to extract information from the data.

4. Interpret the information and draw conclusions.

Two key categories of statistical analysis that may be used while following the above steps are descriptive statistics and statistical inference. Descriptive statistics consists of the presentation of data in tables and charts, as well as a summarization of data by means of graphs and numerical descriptions. Statistical inference consists of generalizations based on sample data. The two are frequently used together when attempting to draw statistical conclusions about data. 
While data may fall under a wide range of distributions, one of the most useful and most common is the normal distribution. The normal distribution consists of continuous random variables that form a bell curve when graphed. Due to its prevalence in statistics, many statistical analysis methods assume the data being analyzed follows a normal distribution. Therefore data that does not naturally follow a normal distribution can be transformed to become more normal. An example of this is time data. Time data is often positively skewed and therefore does not closely follow a normal distribution. However, the data may be transformed using a mathematical equation in order to generate a more normal distribution. Common methods of transforming data include taking the natural log of each data point or taking the log of each data point using a base such as 10 .

One method for determining the normality of data is to conduct an AndersonDarling test for normality in a statistical analysis software package, such as Minitab. A probability plot is generated and plots the data versus a theoretical normal distribution, which results in an approximately straight line if the data is normally distributed. Additionally, a p-value is calculated; for the test of normality, the higher the $p$-value, the closer the data follows a normal distribution. A variety of data analysis methods become available to the analyst once the data resembles a normal distribution.

Although many statistical analysis methods require that the data follow a normal distribution, data resulting from the use of the likert scale, such as with a survey, is often still analyzed using those methods. The likert scale is a psychometric 
scale typically used to scale responses. It consists of statements that the participant selects a level of agreement or disagreement with. The scale typically contains five or seven response levels and is considered balanced because it contains an equal number of positive and negative positions. Controversy surrounds the use of many statistical analysis methods with data collected using a likert scale. Therefore there is little consensus regarding acceptable statistical analysis methods using data resulting from a likert scale.

\subsection{Regression Analysis versus ANOVA}

Two frequently used methods of statistical inference are regression and analysis of variance (ANOVA). While both are used to infer conclusions regarding sample data, the approach to reach the conclusions differ. Regression results in a model that may be used to predict future variable output values and is based on

continuous variables. ANOVA compares variation between two or more variables, such as if a statistically significant difference exists between three sample means, and uses categorical variables. Both methods contain several techniques that account for a variety of sample data situations.

Regression analysis provides one method for analysts to predict future variable outputs by using sample data. It may result in a linear or non-linear model and contain a single or multiple variables. Regardless of the type of regression, the analysis determines the equation of a model that best fits the provided data pairs. The level of fit for the model is determined by minimizing the squared distance between the individual observations and the model line. These individual values 
are also known as residuals. The residuals are used to calculate a coefficient of determination, or $\mathrm{R}^{2}$ value. This value can be interpreted as a percent of variance explained by the independent variable. The closer the $\mathrm{R}^{2}$ value is to one, the better the fit of the model and the more the variance is explained by the independent variable. It should be noted that the regression model works primarily for values within the range of experimentation. This is because the bivariate data may exhibit a different relationship outside the experimentation range. A related analysis to determine the regression model is correlations between variables. A sample correlation coefficient $r$ is calculated and describes the strength and direction of a linear relationship between the two variables. The closer $r$ is to $|1|$, the stronger the relationship; $r$ values close to zero imply a weak linear association. Positive $r$ values reflect a positive correlation, which means that as one variable increases, the other increases as well. Negative $r$ values reflect a negative correlation, signifying that as one variable increases, the other decreases.

Analysis of variance provides analysts with a method for determining if a statistically significant difference exists between calculated sample values, with the most common value being the sample mean. ANOVA can compare a single sample's value, such as its mean, to a set value to determine the statistical significance of the sample value. It can also compare the values of several samples to determine if a significant statistical difference exists between them. In addition to analyzing data, ANOVA may also be used to assist with designing experiments, such as determining the minimum required sample size to collect. 
The concepts described in this literature review provide a basis for the completed analysis. The service quality discussion introduces the concepts used to evaluate a specific restaurant in a case study, while the inferential statistics discussion provides an introduction to the types of statistical analysis conducted in this thesis. The next section outlines the methodology used to explore complete this thesis. 


\section{Chapter 3: Methodology}

\subsection{Using a Location Study}

A study was conducted at a casual dining restaurant in San Luis Obispo, California in order to explore the presence of a definable relationship between operations efficiency and customer satisfaction in the restaurant industry. The study consisted of two sections: a time study and accompanying observations to measure operations efficiency and objective service quality, and a survey given to restaurant patrons to measure customer satisfaction. An analysis of the two sections tested the following hypothesis:

- Customer satisfaction will increase to a peak as operations efficiency increases, at which point customer satisfaction will begin decreasing.

\subsection{Measuring Operations Efficiency}

A time study was used to measure several operations efficiency metrics. The time study determined the average order fulfillment time and the average table turn time for restaurant patrons. The number of employees working during the study was also recorded.

\subsection{Measuring Customer Satisfaction}

The SERVQUAL scale created by Parasuraman et al. (1988) served as the basis for measuring customer satisfaction. The survey presented by the authors was modified to better fit the purpose of this thesis. The survey was shortened from 44 to 32 questions in order to provide restaurant patrons with a survey that could 
be completed in less than five minutes. Questions were eliminated based on the provided factor loading on the service quality dimension to which they belong (Parasuraman, Zeithaml, \& Berry, 1988). Questions with a factor loading below 60 were eliminated, resulting in the 32 questions used for this thesis study, with 16 questions regarding customer expectations of restaurants in general and 16 questions regarding customer perceptions of the specific restaurant location of the study. Additionally, three demographic questions asking about gender, ethnicity, and age were added to the survey used in this study. The survey provided to restaurant patrons can be found in Appendix B. Prior to conducting the study, the survey was evaluated and approved by the Human Subjects Committee at Cal Poly San Luis Obispo.

Objective service quality was measured through a time study conducted at the restaurant. Restaurant patrons were timed throughout their dining experience. Times collected included initial queue time, order fulfillment time, and overall dining experience length. Collected surveys were correlated with the associated wait times for the restaurant patron that submitted the survey.

\subsection{Study Logistics}

A study was conducted on Wednesday, October $2^{\text {nd }}, 2013$ at a restaurant in downtown San Luis Obispo between 11:30 am and 1:30 pm. A second study was conducted at the same location on Friday, November $1^{\text {st }}, 2013$ between 12:15 pm and 1:30 pm. The author of this paper worked with the restaurant owner to select the study times and dates in order to collect data during both busy and 
slow periods. Additionally, the restaurant owner provided an incentive of $\$ 2$ off a future purchase for any patron that completed the survey.

On the days of the study, a graduate industrial engineering student assistant to the paper's author approached restaurant patrons and asked if they would be interested in participating in a survey for a Cal Poly industrial engineering student's master's thesis. She provided a brief overview of the thesis topic and mentioned the incentive provided by the restaurant. If the patron agreed to complete the survey, the student handed him or her a survey and a pen. She instructed patrons to return their completed survey at the end of their meal to this paper's author who was seated in a corner of the restaurant. The incentive was provided to each patron when he or she returned the completed survey.

This paper's author sat in a corner of the restaurant and conducted a time study while an assistant handout out surveys. The time study recorded various times and observations throughout each party's meal. This information included: party arrival time; party size; party register arrival time; party transaction end time; the time the first food item was delivered to the party; the time the last food item was delivered to the party; any order errors when the food was delivered; party departure time; the time the table was bussed; and any additional comments. Times were not collected for patrons that did not volunteer to complete the survey. The data collection sheet used can be found in Appendix B. In addition to collecting times and observations, the author also received completed patron surveys. As patrons returned completed surveys, they were thanked for their 
participation and handed the incentive in the form of a coupon. Each collected survey was then marked with a number that corresponded to the time study entry for that patron.

The following describes the layout of the restaurant used for the study. Customers enter the restaurant used for the study and order before sitting down. The menu is located on a board above the register area and handout menus are available at the entrance to the restaurant. Customers seat themselves either inside or outside after ordering at the register. Customers receive their drinks at the register and restaurant employees bring the food items to the table. Figure 2 shows the layout of the restaurant used in the study. The diagram is not to scale.

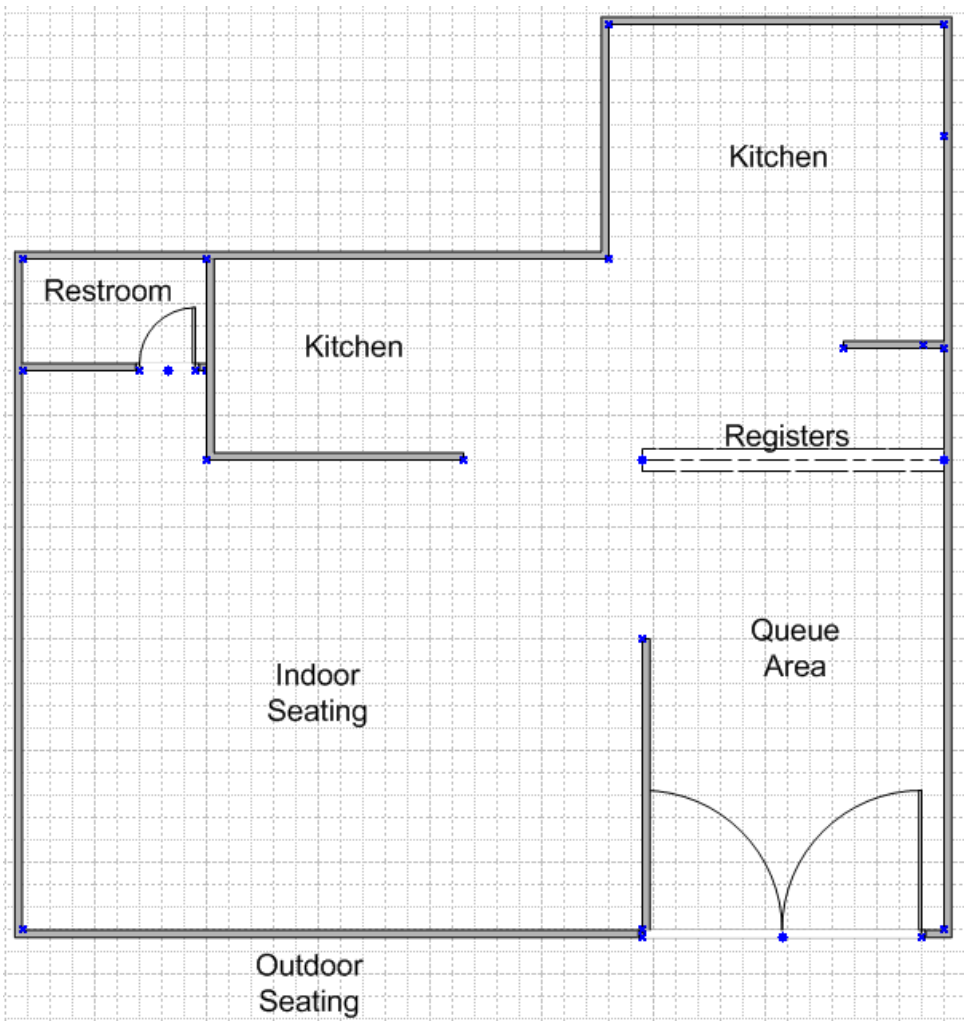

Figure 2. Layout of Restaurant Study Location 


\subsection{Data Analysis}

The first step in the data analysis process involved cleaning the collected data and checking for normality. Correlations were then run on the variables in order to determine which to focus on with further analysis. Finally linear, multiple, and non-linear regression were used to develop predictive models.

The next chapter presents the results obtained by following the methodology described in this chapter. 


\section{Chapter 4: Results}

\subsection{Data Cleaning}

Data analysis began with inputting all collected survey and time study data into an Excel spreadsheet. Excel was used as the initial data analysis tool because it allows for easier data organization and cleaning than Minitab. The collected data was cleaned in several stages after it was entered into the Excel spreadsheet. Each stage of the data cleaning process generated a new tab in order to preserve all data throughout each stage.

Columns containing time calculations were added to the time study data spreadsheet. These calculations included the following: the queue wait time, which is the difference between the register arrival time and the restaurant arrival time; the transaction time, which is the difference between the transaction end time and register arrival time; the order wait time, which is the difference between the time the first food item was delivered and the transaction end time; the order delivery time, which is the difference between the time the last food item was delivered and the time the first food item was delivered; the complete order fulfillment time, which is the sum of the order wait time and order delivery time; and the total service time, which is the total time between when a customer enters the restaurant until all ordered items have been delivered. Figure 3 on the next page provides a visual representation of the timeline for the collected times for each patron. 


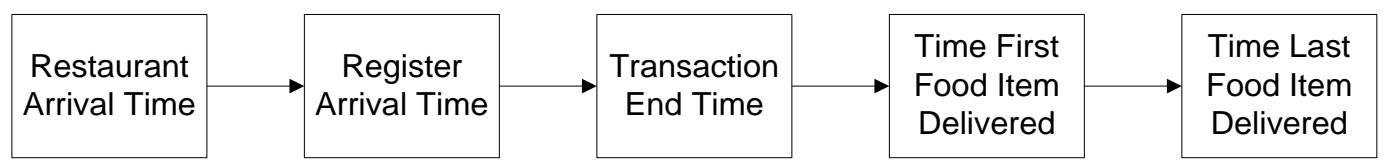

Figure 3. Restaurant Study Timeline

The original data was consulted for any entry that resulted in a negative calculated time to check for data entry errors; any correct entry that resulted in a negative calculated time was removed from the data to be analyzed. Additionally, any entry that did not include all of the following was removed: arrival time, register arrival time, transaction end time, time first food item was delivered, and time last food item was delivered.

After inputting the customer survey data on a separate tab from the time study data, all negatively phrased statements were reverse-scored, as advised by the survey creator, Parasuraman et al. (1988). Following the reverse-scoring of the customer survey data, a matrix was created that displayed the customer survey data and time study data in a single tab. The data was further cleaned by removing any entries that did not have both cleaned customer survey data and cleaned time study data. Therefore any completed customer surveys without a corresponding time study entry, or any time study entries without a corresponding completed customer survey, were removed. This resulted in a sample size of 34. Several customer survey data averages were calculated after creating the cleaned data matrix. As each survey question corresponds to one of the five dimensions of service quality discussed by Parasuraman et al. (1988), the average response for each service dimension, by survey responder, was 
calculated. For example, the first three questions on the survey pertained to the tangibles dimension for customer expectations in restaurants. Therefore the responses to the first three questions were averaged in order to obtain the service quality measure of customer expectations in the tangibles dimension for each survey entry. Additionally, the overall average expectations of customers across all five dimensions in restaurants and the overall average perceptions of customers across all five dimensions at the specific location of the study were also calculated. The final cleaned data matrix is located in Appendix A.

\subsection{Data Validation}

After creating the cleaned data matrix, data was copied into Minitab in order to complete the statistical analysis. Analysis began with calculating basic descriptive statistics for both the time study and survey data in order to confirm that the data made sense. Statistics calculated included the mean, standard deviation, minimum, and maximum values. The survey data used a likert scale with one representing the lowest value and seven representing the highest value, while the time data is shown in minutes. Table 1 on the next page summarizes the descriptive statistics for all of the study data combined. The descriptive statistics generated by study day are located in Appendix A. 
Table 1. All Study Data Descriptive Statistics

\begin{tabular}{|r|r|r|r|r|}
\hline & \multicolumn{1}{l|}{ Mean } & \multicolumn{1}{l|}{ StDev } & Minimum & Maximum \\
\hline Tangibles - E & 5.578 & 1.369 & 1.000 & 7.000 \\
\hline Tangibles - P & 5.740 & 0.951 & 3.000 & 7.000 \\
\hline Reliability - E & 6.066 & 1.437 & 1.000 & 7.000 \\
\hline Reliability - P & 5.748 & 1.034 & 3.750 & 7.000 \\
\hline Responsiveness - E & 5.265 & 1.011 & 3.333 & 7.000 \\
\hline Responsiveness - P & 5.863 & 1.045 & 3.000 & 7.000 \\
\hline Assurance - E & 6.574 & 1.045 & 1.000 & 7.000 \\
\hline Assurance - P & 5.779 & 1.426 & 1.000 & 7.000 \\
\hline Empathy - E & 5.341 & 1.265 & 1.250 & 7.000 \\
\hline Empathy - P & 5.985 & 0.904 & 4.000 & 7.000 \\
\hline Overall - E & 5.706 & 0.925 & 1.688 & 6.813 \\
\hline Overall - P & 5.831 & 0.639 & 4.438 & 7.000 \\
\hline Queue Wait Time (min) & 1.240 & 0.953 & 0.033 & 3.633 \\
\hline Transaction Time (min) & 0.954 & 0.451 & 0.300 & 2.150 \\
\hline Order Wait Time (min) & 6.658 & 3.565 & 0.867 & 14.667 \\
\hline Order Delivery Time (min) & 4.246 & 2.324 & 1.183 & 8.217 \\
\hline Total Service Time (min) & 8.781 & 4.135 & 0.867 & 15.567 \\
\hline & & 4.208 & 1.500 & 16.400 \\
\hline Complete Order Fulfill Time (min) & 8.785 & & & \\
\hline
\end{tabular}

The data was tested for normality after checking the basic descriptive statistics. As time data is often positively skewed, additional normality tests were conducted with transformed time study data. The time study data was transformed to the natural log of the original time study data. The p-values resulting from the Anderson-Darling normality tests were compared between the original time study data and transformed time study data. The data type that resulted in a higher $\mathrm{p}$-value (original data versus transformed data) indicated which data type was more normal; therefore the data type with the higher p-value for each time study data category was selected for use in the following analysis steps. The table comparing the $p$-values is located in Appendix A. The original 
calculated times were used for the following: order wait time, complete order fulfillment time, and total service time. The transformed data times were used for the following: queue wait time, transaction time, and order delivery time. It should be noted that the analysis performed compared the time study data with the second half of the survey questions only. These questions related to customer perceptions about the study restaurant and not customer expectations for restaurants in general. The perception questions were used because they alone related directly to the customers' actual experience when the time study data was collected and therefore provided a better data source to determine the effect of efficiency on customer satisfaction. Additionally, the perceptions survey data was not transformed before analysis. The survey data was analyzed in the likert scale format, following the examples of Alrousan (Alrousan \& Abuamond, 2013) and Fine (Fine \& Clark, 2013).

In addition to testing the data for normality, the collected study data was compared between study days in order to determine if there was a significant difference between the data collected over the two different days. A two-sample t-test was conducted for the means between the days for each study metric collected. The comparison confirmed that the data collected between the two days was not significantly different, therefore allowing for the data from both days to be combined and analyzed together. The resulting $p$-values are shown on the next page in Table 2. The Minitab outputs for each two-sample t-test can be found in Appendix A. 
Table 2. Two-Sample T-Test between Study Days P-Values

\begin{tabular}{|r|r|}
\hline & P-Value \\
\hline Tangibles & 0.851 \\
\hline Reliability & 0.846 \\
\hline Responsivness & 0.727 \\
\hline Assurance & 0.073 \\
\hline Empathy & 0.455 \\
\hline Overall & 0.364 \\
\hline Queue Wait Time & 0.643 \\
\hline Transaction Time & 0.175 \\
\hline Order Wait Time & 0.244 \\
\hline Order Delivery Time & 0.267 \\
\hline Complete Order Fulfill Time & 0.361 \\
\hline Total Service Time & 0.279 \\
\hline
\end{tabular}

\subsection{Regression Analysis}

Once the data was tested for normality and the data from the two studies combined, a correlation matrix was created to determine potential correlations between the time study data (used to measure restaurant efficiency) and the survey data (used to measure customer satisfaction). Often data relating to social sciences considers lower correlation coefficients noteworthy, which allowed for considering correlations with a coefficient $r>=|0.3|$ to be considered noteworthy and used for further analysis. Additionally, the p-values for the four correlations between the "tangibles" dimension and a wait time are all significant below $10 \%$. Table 3 on the next page summarizes the five noteworthy correlations and their p-values; the entire correlation matrix can be found in Appendix A. 
Table 3. Significant Correlation Coefficient Summary

\begin{tabular}{|r|r|r|}
\hline & $\begin{array}{l}\text { Correlation } \\
\text { Coefficient }\end{array}$ & \multicolumn{1}{l|}{ P-Value } \\
\hline Order Wait Time and Tangibles & -0.3781 & 0.027 \\
\hline Total Service Time and Tangibles & -0.3748 & 0.029 \\
\hline Complete Order Fulfillment Time and Tangibles & -0.3535 & 0.040 \\
\hline Queue Wait Time and Tangibles & -0.3084 & 0.076 \\
\hline Order Delivery Time and Assurance & -0.3063 & 0.232 \\
\hline
\end{tabular}

Four of the five noteworthy correlations relate to the "tangibles" dimension of service quality. This shows that customer satisfaction is affected most directly by the more visible aspects of a restaurant, namely the appearance of the equipment, facilities, and staff. The negative correlations between the tangibles dimension and the order wait time, total service time, complete order fulfillment time, and queue wait time show that as the wait times goes down, customers' views of the equipment, facilities, and staff goes up. The negative correlation between order delivery time and assurance shows that the restaurant staff inspires more trust and confidence with shorter order delivery times.

After determining the noteworthy correlations between the time study data and survey data, potential regression curves were determined. Linear regression models were created using the variables with noteworthy correlations in the correlations matrix. The strongest correlation, between order wait time and the tangibles dimensions, was considered first. A linear regression model predicting the tangibles dimension value based on the order wait time was calculated using Minitab. After calculating this first model, the variable with the next strongest correlation between itself and the tangibles dimension was added, thus beginning 
multiple regression analysis. If the resulting adjusted $R^{2}$ value increased, the variable was kept in the regression model. However, if the resulting adjusted $R^{2}$ value decreased, the variable was removed from the regression model. Therefore the second regression model generated predicted the tangibles dimension value based on both the order wait time and the total service time. However, this resulted in a lower adjusted $R^{2}$ value, indicating that the additional variable did not increase the accuracy of the model. Therefore the total service time variable was removed from the model before creating the next regression model iteration.

The remaining two variables added to the initial tangibles dimension value and order wait time regression model resulted in a lower adjusted $\mathrm{R}^{2}$ value. This resulted in the use of the linear regression model containing only the tangibles dimension value and the order wait time. The adjusted $R^{2}$ value was $11.6 \%$ with a regression equation of:

$$
\text { Tangibles }=6.41-0.101 * \text { Order Wait Time }
$$

An additional polynomial regression model was calculated using the same two variables; this model resulted in a higher adjusted $R^{2}$ value, indicating that the polynomial regression model provides a better fit. This model is shown below in Figure 4. The polynomial regression model adjusted $R^{2}$ value was $14.7 \%$ with a regression equation of:

$$
\text { Tangibles }=5.715+0.1483 * \text { Order Wait Time }-0.01699 * \text { Order Wait Time }{ }^{2}
$$




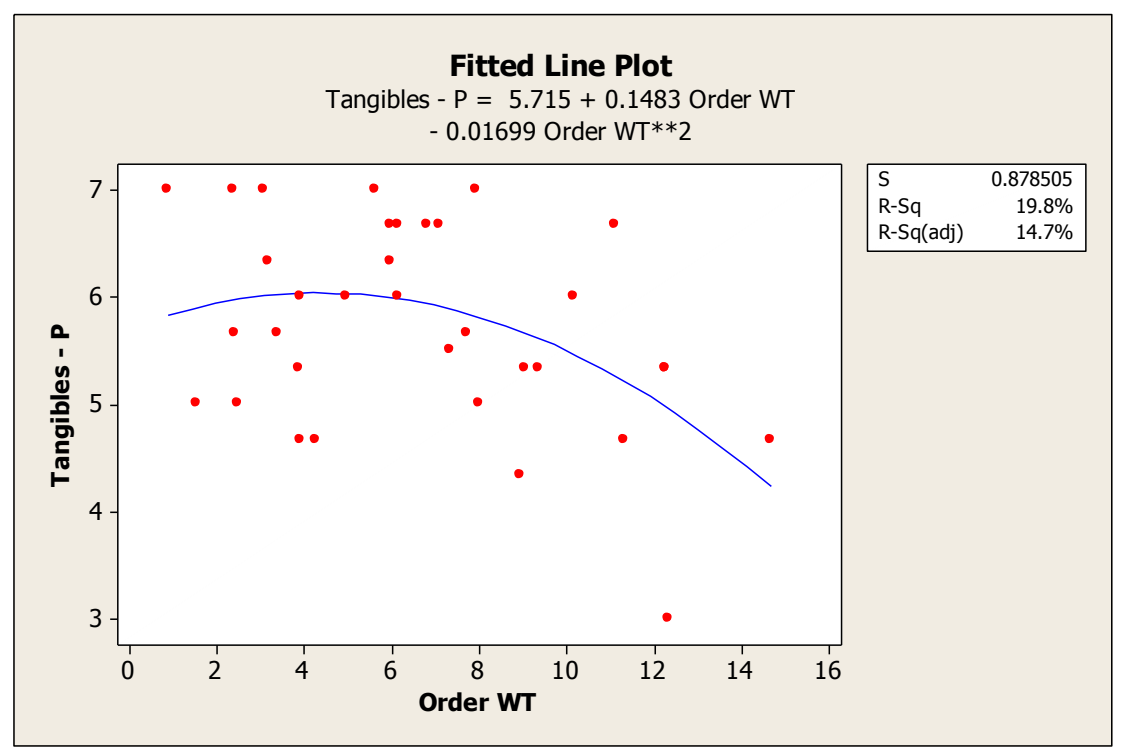

Figure 4. Polynomial Regression Curve, Tangibles vs. Order Wait Time

Finally, a regression model was created for the assurance dimension variable and the order delivery time, as this was the fifth noteworthy correlation from the correlation matrix. Its resulting adjusted $R^{2}$ value was $3.3 \%$ with a regression equation of:

$$
\text { Assurance }=6.88-0.592 * \ln (\text { Order Delivery Time })
$$

The full regression analysis output for the three models described above can be found in Appendix A.

\subsection{Customer Expectations versus Perceptions}

One application of the original SERVQUAL survey developed by Parasuraman et al. (1988) is to compare customer expectations of a service type with perceptions of their experience at a specific location in that same service industry. For this thesis, customer expectations of restaurants in general were compared to their 
perceptions of the restaurant location of the study. The comparison was done using two-sample t-tests for each dimension of service quality. The resulting $\mathrm{p}$ values are shown below in Table 4.

Table 4. Customer Expectation vs. Perceptions Two-Sample T-Test P-Values

\begin{tabular}{|r|r|}
\hline & P-Value \\
\hline Tangibles & 0.574 \\
\hline Reliability & 0.298 \\
\hline Responsiveness & 0.019 \\
\hline Assurance & 0.011 \\
\hline Empathy & 0.019 \\
\hline Overall & 0.518 \\
\hline
\end{tabular}

Using a level of significance of $5 \%$ results in a failure to reject the hypothesis that there is a statistically significant difference between the two sample means for the tangibles and reliability dimensions, as well as the overall survey average. The results of the two-sample t-tests show that there is a statistically significant difference between the two sample means for the responsiveness, assurance, and empathy dimensions. By comparing the sample means for customer expectations to customer perceptions in these three dimensions, it can be seen that customer perceptions has a higher mean than customer expectations for the responsiveness and empathy dimensions, while the reverse is true for the assurance dimension.

The next chapter discusses the meaning and implications of the results presented in this chapter. 


\section{Chapter 5: Discussion}

\subsection{Regression Discussion}

Due to the large number of variables that can affect the results of the data analysis, the conclusions drawn by this thesis directly relate to similar types of restaurants as the one used in the study. Additionally, the meal period may affect the results, indicating that the results discussed in this chapter relate to the lunch period. The customer demographics may also affect the results. Based on the demographics of the customers that participated in the survey, the results relate to customers ranging in age from 18 to 64 across a variety of ethnic backgrounds.

The negative correlations between the "tangibles" dimension and the order wait time, total service time, complete order fulfillment time, and queue wait time show that as the wait times goes down, customers' views of the equipment, facilities, and staff goes up. This implies that customers believe that newer and cleaner equipment, facilities, and staff leads to shorter wait times. Therefore restaurant managers can consider cleaning or upgrading their equipment and facilities and maintaining a high level of cleanliness and hygiene requirements for their staff in order to improve their customers' opinions regarding the tangibles dimension.

The regression analysis determined that a polynomial equation provided the best fit for a regression curve between the tangibles dimension value and order wait time. The curve shows that the tangibles dimension value is affected more when 
the order wait time is longer. While the curve gently slopes positively on the lefthand side, the tangibles dimension value remains relatively constant until around the 8 minute mark; at this point the curve begins to slope more strongly in the negative direction, indicating that the more the order wait time increases, the more it begins to affect the tangibles dimension value. This result indicates that shorter order wait times do not negatively affect the tangibles dimension value much, but rather longer order wait times more strongly affect the tangibles dimension value. Furthermore, as the tangibles dimension value contained four of the five significant correlations, this dimension can be used as a measure for customer satisfaction.

Therefore based on the regression curve, restaurant owners and managers should focus on reducing the customer order wait time because reducing this time results in higher levels of customer satisfaction. Even if the order wait time is reduced beyond the peak of the curve, the faster times do not result in significantly lower levels of customer satisfaction. This means that restaurants can focus on improving their efficiency without hurting customer satisfaction. As a result, restaurants can choose to increase revenue by improving their efficiency. Faster order wait times enable customers to complete their meals quicker, which in turn allows for a higher customer throughput. This higher throughput results in larger revenue per available seat hour, signifying that the restaurant is increasing revenue while effectively utilizing its available seating. 


\subsection{Customer Expectations versus Perceptions Discussion}

The results of the two-sample t-test comparing the customer expectations versus perceptions survey results implies that customers believe that the restaurant study location exceeds the expectations its customers have for restaurants in general with regards to the responsiveness and empathy dimensions, while the restaurant study location does not meet the expectations its customers have for restaurants in general with regards to the assurance dimension. The two-sample t-test results for the remaining two dimensions and the overall rating all signify that the study restaurant location meets the expectations its customers have for restaurants in general.

\subsection{Future Directions}

For service industries, the added complexity brought on by the individualism of its customers as a factor determining the quality of the provided service results in a challenge unique to service industries. As a result, many within the service industries hesitate to improve the efficiency of their service because they fear decreasing the satisfaction of their customers. Therefore understanding the relationship between operations efficiency and customer satisfaction is crucial to creating a successful service business. Although this thesis investigated the relationship specifically at restaurants, a similar approach could be used for any service industry. 


\section{Bibliography}

Ahrens, T., \& Chapman, C. S. (2004). Accounting for Flexibility and Efficiency: A Field Study of Management Control Systems in a Restaurant Chain. Contemporary Accounting Research, 271-301.

Alrousan, R. M., \& Abuamond, I. M. (2013). The Mediation of Tourists Satisfaction on the Relationship between Tourism Service Quality and Tourists Loyalty: Five Stars Hotel in Jordanian Environment. International Business Research, 79-90.

Anonymous. (2003). A Plan to Boosting Restaurant Efficiency. Industrial Engineer, 15.

Bertsimas, D., \& Shioda, R. (2003). Restaurant Revenue Management. Operations Research, 472-506.

Carrillat, F. A., Jaramillo, F., \& Mulki, J. P. (2007). The Validity of the SERVQUAL and SERVPERF Scales: A Meta-Analytic View of 17 Years of Research Across Five Continents. International Journal of Service Industry Management, 472-490.

Ceschini, S. (2005). Analyzing Risk in the Restaurant Industry. ProQuest Dissertations and Theses. Oklahoma State University.

Cronin, J. J., \& Taylor, S. A. (1992). Measuring Service Quality: A Reexamination and Extension. Journal of Marketing, 55-68.

Fine, M., \& Clark, P. (2013). Examining Antecedents of Satisfaction for Marketing/Management Students in Higher Education. Research in Higher Education Journal, 1-8.

Garvin, D. A. (1983). Quality on the Line. Harvard Business Review, 65-75. 
Gupta, S., Edward, M., \& Gomez, M. (2007). Guest Satisfaction and Restaurant Performance. Cornell Hotel and Restaurant Administration Quarterly 48(3), 284-298.

Hanks, R. D., Cross, R. G., \& Noland, R. P. (2002). Discounting in the Hotel Industry: A New Approach. Cornell Hotel and Restaurant Administration Quarterly, 94-103.

Johnson, R. A. (2011). Probability and Statistics for Engineers. Boston: Pearson Education, Inc.

Kimes, S. E. (1999). Implementing Restaurant Revenue Management. Cornell Hotel and Restaurant Administration Quarterly, 16-21.

Kimes, S. E. (2004). Restaurant Revenue Management: Implementation at Chevys Arrowhead. Cornell Hotel and Restaurant Administration Quarterly, 52-67.

Kimes, S. E., \& Robson, S. K. (2004). The Impact of Restaurant Table Characteristics on Meal Duration and Spending. Cornell Hotel and Restaurant Administration Quarterly, 333-346.

Kimes, S. E., Wirtz, J., \& Noone, B. M. (2002). How Long Should Dinner Take? Measuring Expected Meal Duration for Restaurant Revenue Management. Journal of Revenue and Pricing Management, 220-233.

Lam, S. S., \& Woo, K. S. (1997). Measuring Service Quality: A Test-Retest Reliability Investigation of SERVQUAL. Journal of the Market Research Society, 381-396.

Montgomery, D. C. (2009). Introduction to Statistical Quality Control. Jefferson City: R. R. Donnelley. 
Murphy, K. S. (2009). Strategic Human Resource Management Performance Metrics for Unit-Level Managers: An Exploratory Study of U.S. Casual Restaurants. Florida International University Hopsitality Review, 20-41. National Restaurant Association. (2013). 2013 Restaurant Industry Pocket Factbook. Retrieved from National Restaurant Association: http://www.restaurant.org/Downloads/PDFs/NewsResearch/Factbook2013_LetterSize.pdf

Oliver, R. L. (1981). Measurement and Evaluation of Satisfaction Processes in Retail Settings. Journal of Retailing, 25-48.

Parasuraman, A. (1985). A Conceptual Model of Sercie Quality and Its Implications for Future Research. Journal of Marketing, 41-50.

Parasuraman, A., Zeithaml, V. A., \& Berry, L. L. (1988). SERVQUAL: A MultipleItem Scale for Measuring Consumer Perceptions of Service Quality. Journal of Retailing, 12-40.

(2012, November 27). Research and Markets: 2013 U.S. Fast Food Restaurants Industry - Industry \& Market Report.

Reynolds, D., \& Thompson, G. M. (2002). Multiunit Restaurant-Productivity Assessment: A Test of Data-Envelopment Analysis. Ithaca: Center for Hospitality Research at Cornell University.

Shearer, B. (2000). Casual Dining Firms Eye M\&A as Internal Growth Hits Limit, 35(8). Mergers and Acquisitions, 40-42.

Sheridan, M. (2003). Timing Table Turns. Restaurants \& Institutions, 83-84.

Sill, B. (2002). Brand Metrics Can Help Restaurant Service Measure Up to Customer Expectations. Nation's Restaurant News, 24-25. 
Soba, M., \& Aydin, E. (2011, December). Ethical Approach to Fast Food

Production Contents and Their Advertisement Strategies 2(24). International Journal of Business and Social Science.

Sweeney, J. C., Johnson, L. W., \& Armstrong, R. W. (1992). The Effect of Cues on Service Quality Expectations and Service Selection in a Restaurant Setting. The Journal of Services Marketing, 15-22.

Thompson, G. M., \& Kwortnik, R. J. (2008). Pooling Restaurant Reservations to Increase Service Efficiency. Journal of Service Research, 335-346.

WebFinance, Inc. (2013). Full Service Restaurant. Retrieved from BusinessDictionary.com: http://www.businessdictionary.com/definition/full-service-restaurant.html 


\section{Appendices}

\section{Appendix A: Supporting Tables and Figures}

Descriptive Statistics: Study Day 10/02/2013

\begin{tabular}{|r|r|r|r|r|} 
& \multicolumn{1}{|l|}{ Mean } & \multicolumn{1}{l|}{ StDev } & Minimum & Maximum \\
\hline Tangibles - E & 5.472 & 1.545 & 1.000 & 7.000 \\
\hline Tangibles - P & 5.757 & 1.062 & 3.000 & 7.000 \\
\hline Reliability - E & 5.990 & 1.643 & 1.000 & 7.000 \\
\hline Reliability - P & 5.726 & 1.082 & 3.750 & 7.000 \\
\hline Responsiveness - E & 5.431 & 1.033 & 3.333 & 7.000 \\
\hline Responsiveness - P & 5.819 & 1.031 & 4.333 & 7.000 \\
\hline Assurance - E & 6.583 & 1.213 & 1.000 & 7.000 \\
\hline Assurance - P & 5.542 & 1.539 & 1.000 & 7.000 \\
\hline Empathy - E & 5.483 & 1.216 & 1.250 & 7.000 \\
\hline Empathy - P & 5.927 & 1.033 & 4.000 & 7.000 \\
\hline Overall - E & 5.734 & 1.051 & 1.688 & 6.813 \\
\hline Overall - P & 5.776 & 0.706 & 4.438 & 7.000 \\
\hline Queue Wait Time & 1.290 & 0.971 & 0.033 & 3.633 \\
\hline Transaction Time & 0.875 & 0.397 & 0.300 & 2.050 \\
\hline Order Wait Time & 6.238 & 3.795 & 0.867 & 14.667 \\
\hline Order Delivery Time & 4.768 & 2.089 & 2.017 & 7.983 \\
\hline Complete Order Fulfill Time & 8.424 & 4.558 & 0.867 & 15.567 \\
\hline Total Service Time & 9.299 & 4.600 & 1.500 & 16.400 \\
\hline & & & &
\end{tabular}


Descriptive Statistics: Study Day 11/01/2013

\begin{tabular}{|r|r|r|r|r|} 
& \multicolumn{1}{|l|}{ Mean } & \multicolumn{1}{|l|}{ StDev } & Minimum & Maximum \\
\hline Tangibles - E & 5.833 & 0.820 & 4.667 & 7.000 \\
\hline Tangibles - P & 5.700 & 0.656 & 4.667 & 6.667 \\
\hline Reliability - E & 6.250 & 0.791 & 5.000 & 7.000 \\
\hline Reliability - P & 5.800 & 0.963 & 4.250 & 7.000 \\
\hline Responsiveness - E & 4.867 & 0.878 & 3.667 & 6.333 \\
\hline Responsiveness - P & 5.967 & 1.127 & 3.000 & 7.000 \\
\hline Assurance - E & 6.550 & 0.497 & 5.500 & 7.000 \\
\hline Assurance - P & 6.350 & 0.944 & 4.000 & 7.000 \\
\hline Empathy - E & 5.000 & 1.379 & 3.000 & 7.000 \\
\hline Empathy - P & 6.125 & 0.489 & 5.250 & 7.000 \\
\hline Overall - E & 5.638 & 0.551 & 4.813 & 6.313 \\
\hline Overall - P & 5.963 & 0.444 & 5.313 & 6.813 \\
\hline Queue Wait Time & 1.120 & 0.946 & 0.033 & 2.833 \\
\hline Transaction Time & 1.143 & 0.534 & 0.633 & 2.150 \\
\hline Order Wait Time & 7.665 & 2.863 & 3.383 & 11.300 \\
\hline Order Delivery Time & 3.289 & 2.618 & 1.183 & 8.217 \\
\hline Complete Order Fulfill Time & 9.638 & 2.903 & 3.883 & 13.283 \\
\hline Total Service Time & 10.782 & 3.020 & 5.367 & 14.850 \\
\hline & & & &
\end{tabular}

Raw Time Data (min) versus Transformed Time Data P-Value Comparison

\begin{tabular}{|r|r|r|}
\hline & Raw Data & $\operatorname{In}$ (Raw Data) \\
\hline Queue Wait Time & 0.130 & 0.183 \\
\hline Transaction Time & $<0.005$ & 0.016 \\
\hline Order Wait Time & 0.381 & 0.183 \\
\hline Order Delivery Time & 0.116 & 0.745 \\
\hline Complete Order Fulfill Time & 0.579 & 0.005 \\
\hline Total Service Time & 0.312 & 0.007 \\
\hline
\end{tabular}




\section{Cleaned Data Matrix}

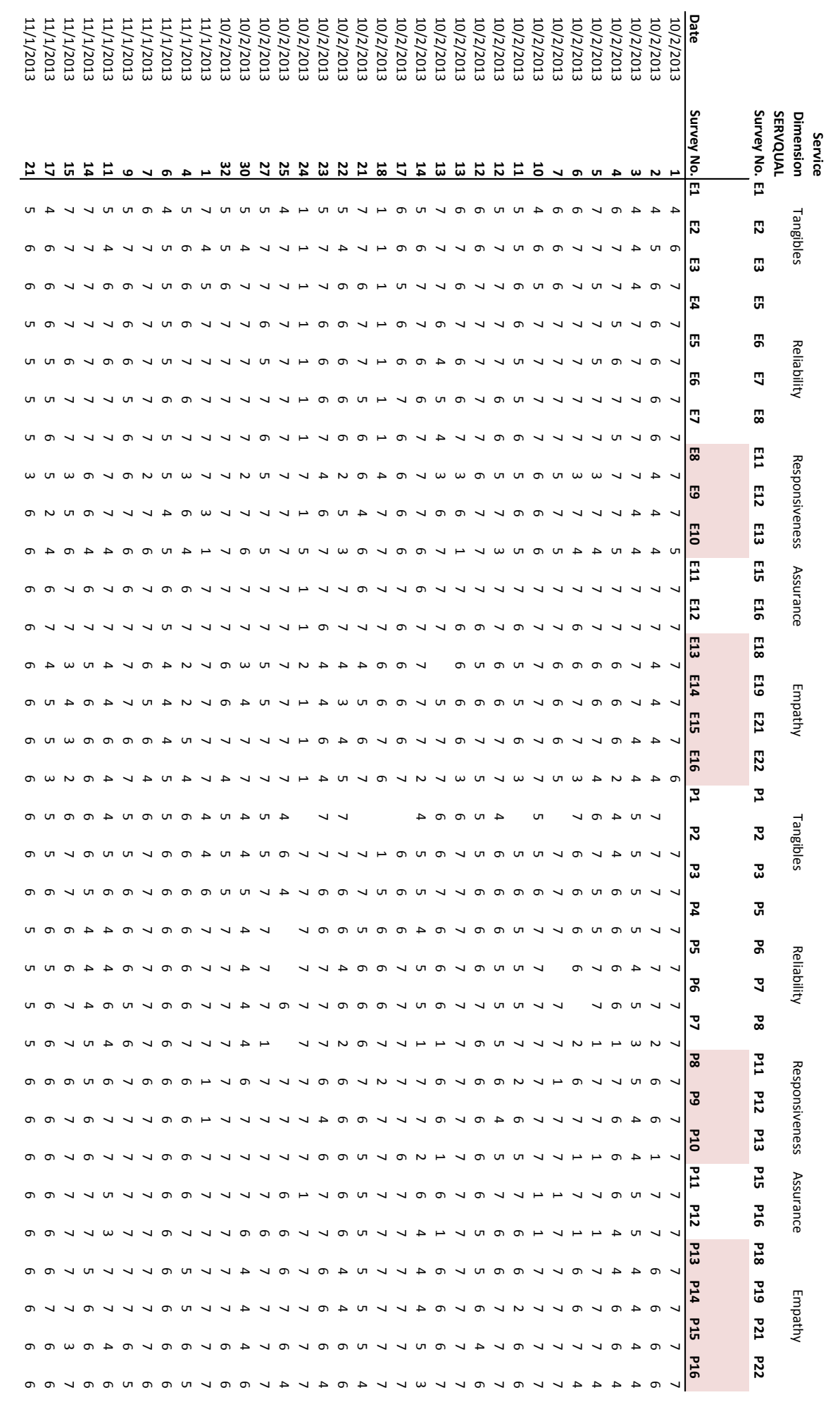




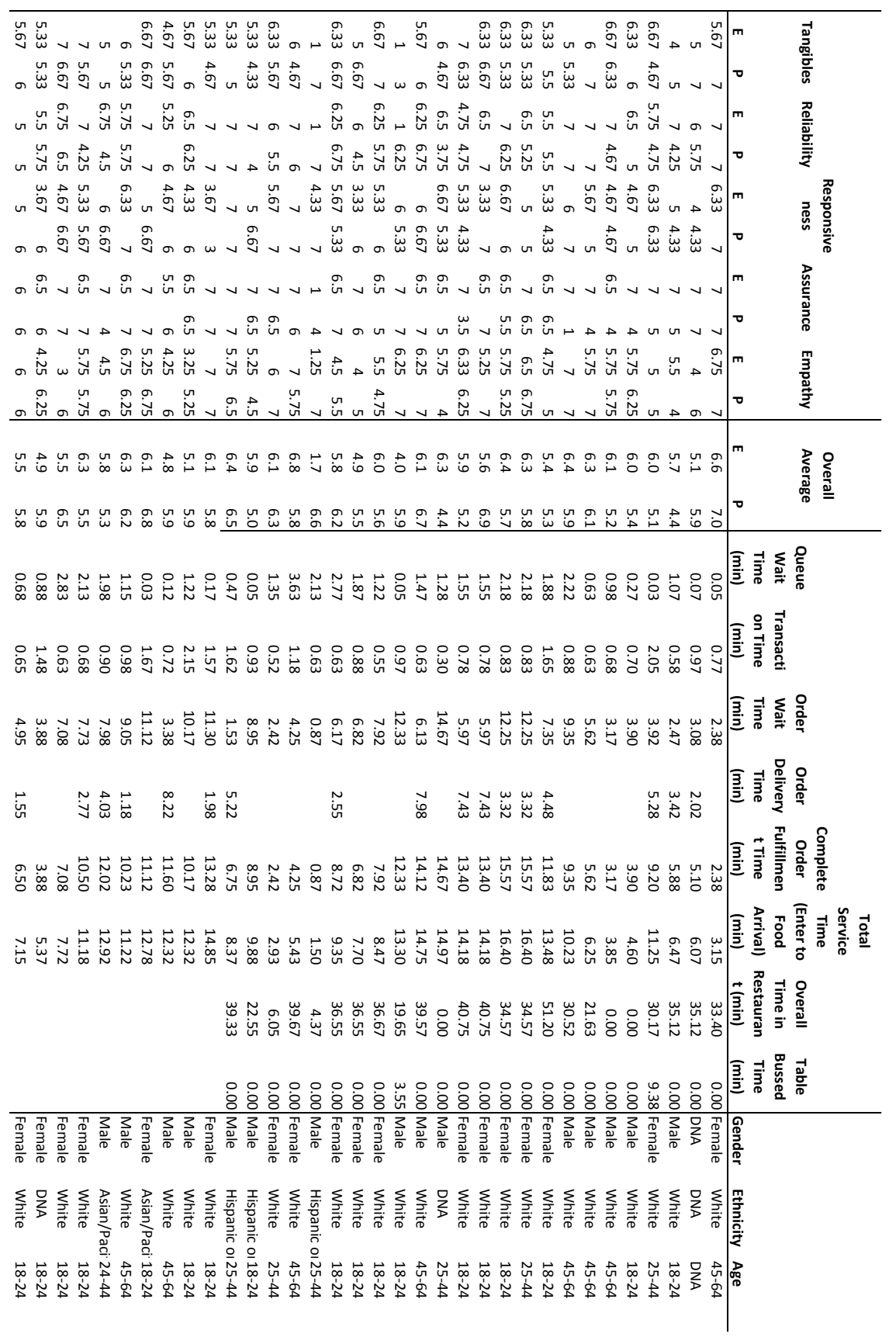




\section{Two-Sample T-Test Minitab Outputs}

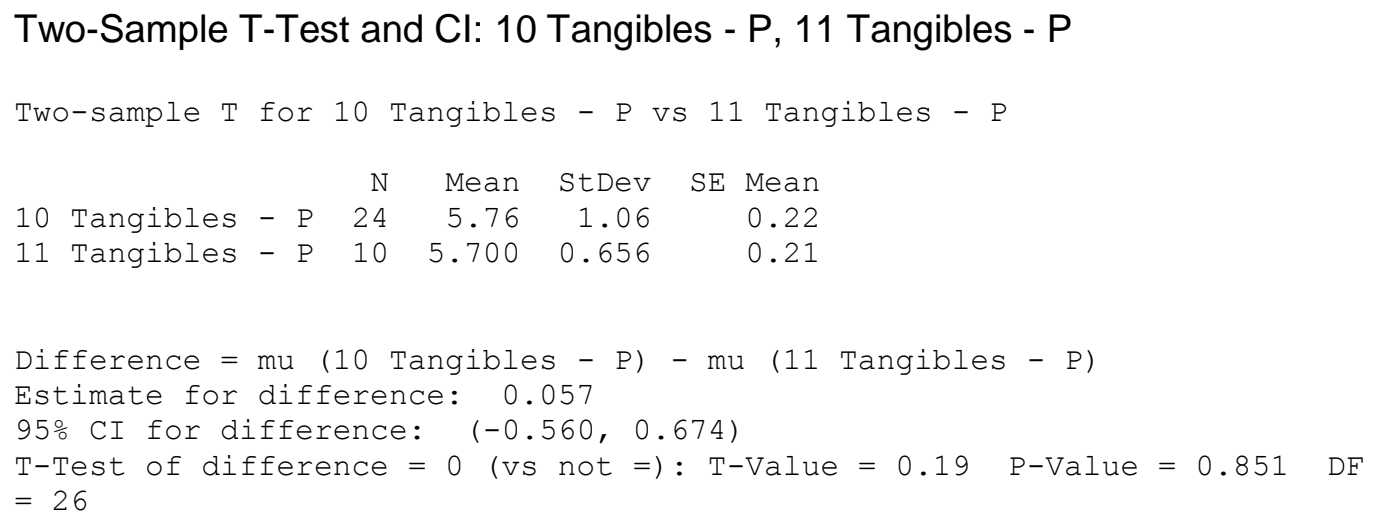

\section{Two-Sample T-Test and CI: 10 Reliability - P, 11 Reliability - P}

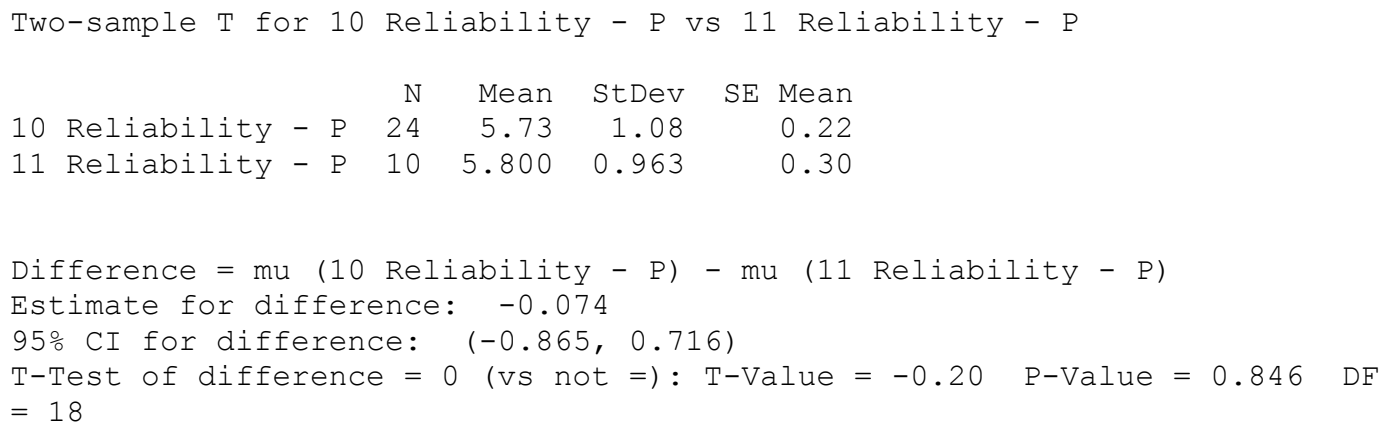

\section{Two-Sample T-Test and Cl: 10 Responsiveness - P, 11 Responsiveness - P}

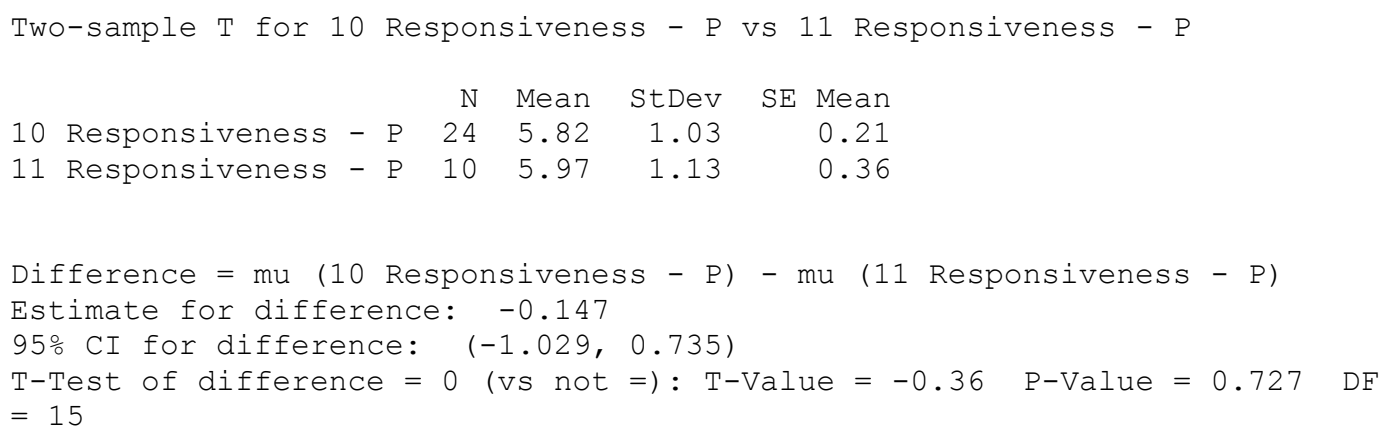




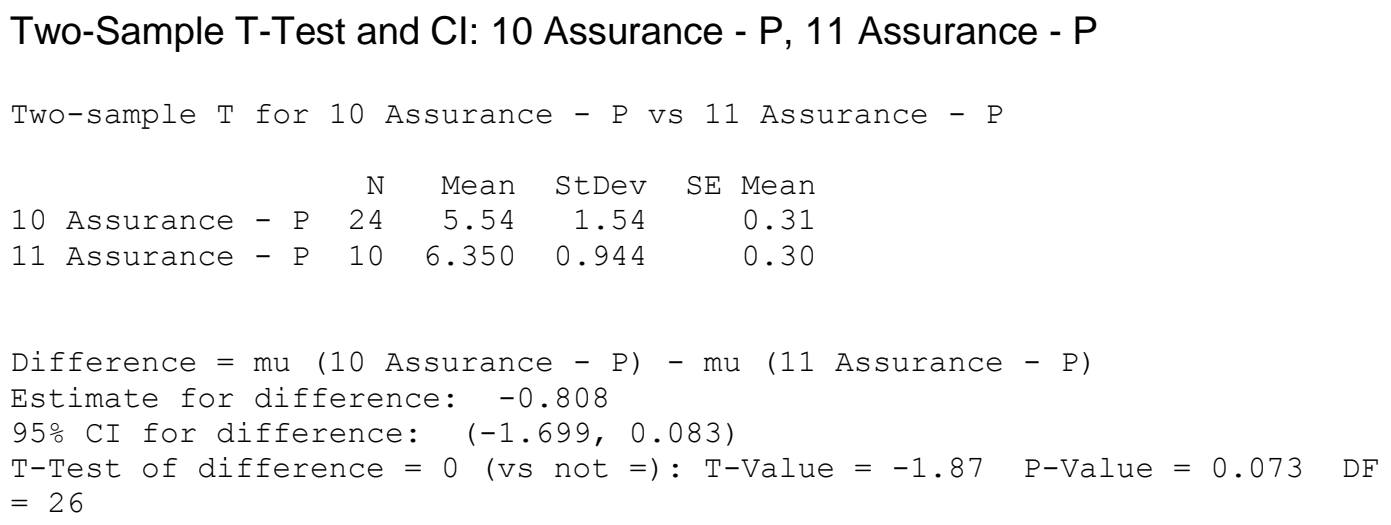

Two-Sample T-Test and Cl: 10 Empathy - P, 11 Empathy - P

Two-sample T for 10 Empathy - P vs 11 Empathy - P

$\begin{array}{llrrrr} & & \text { N } & \text { Mean } & \text { StDev } & \text { SE Mean } \\ 10 & \text { Empathy - P } & 24 & 5.93 & 1.03 & 0.21 \\ 11 \text { Empathy - P } & 10 & 6.125 & 0.489 & 0.15\end{array}$

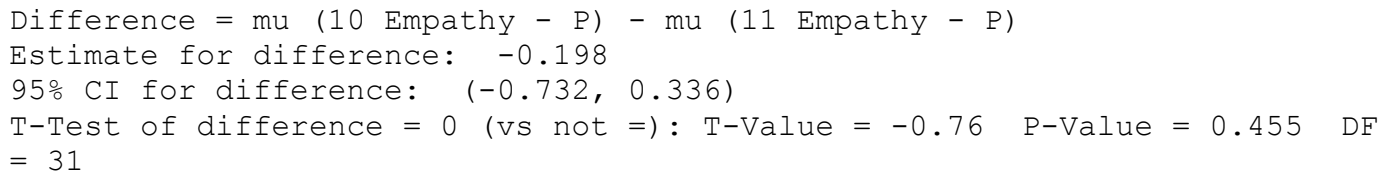

\section{Two-Sample T-Test and Cl: 10 Overall - P, 11 Overall - P}

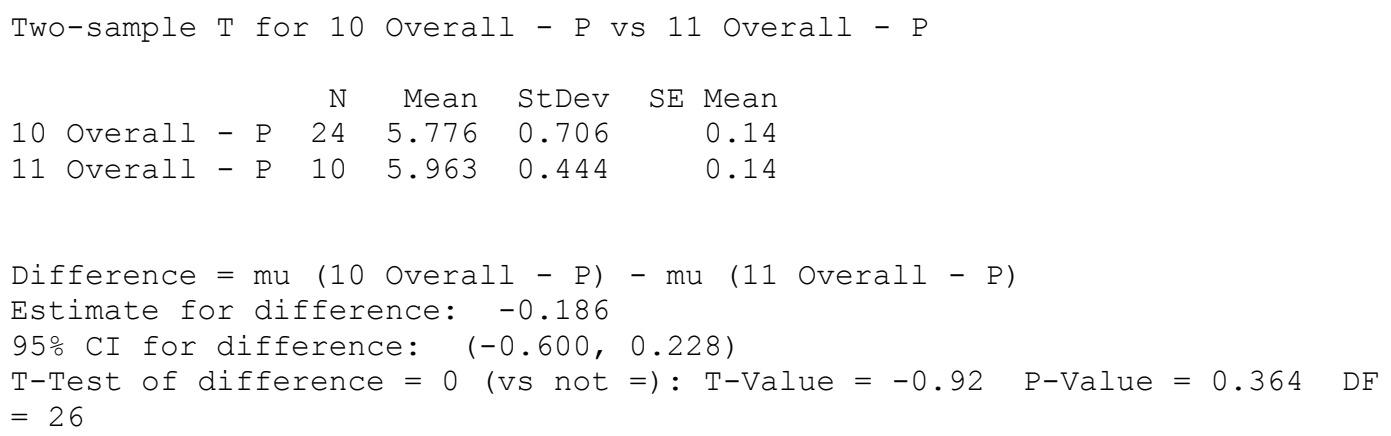




\section{Two-Sample T-Test and Cl: 10 Queue WT, 11 Queue WT}

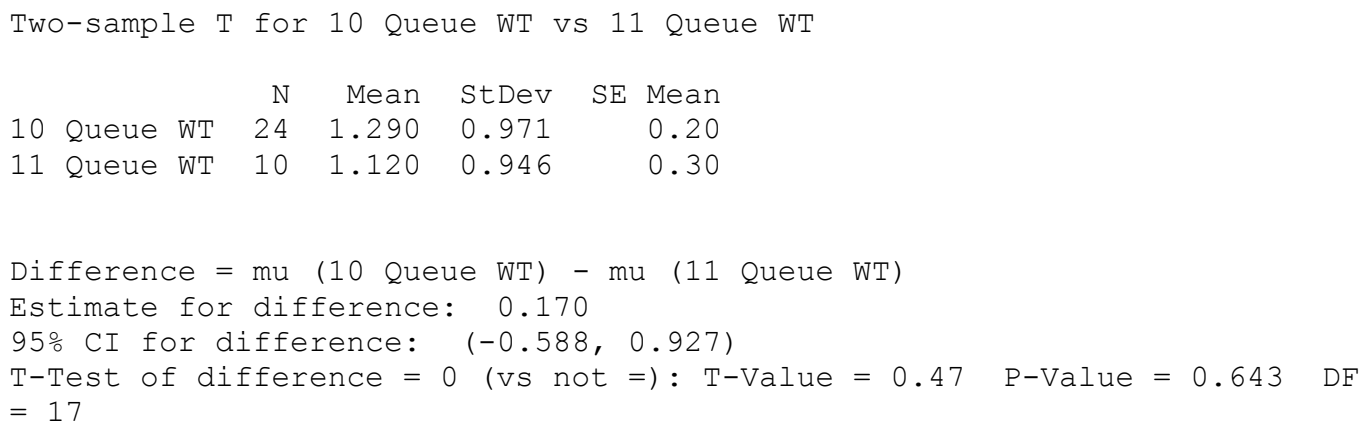

\section{Two-Sample T-Test and Cl: 10 Transaction Time, 11 Transaction Time}

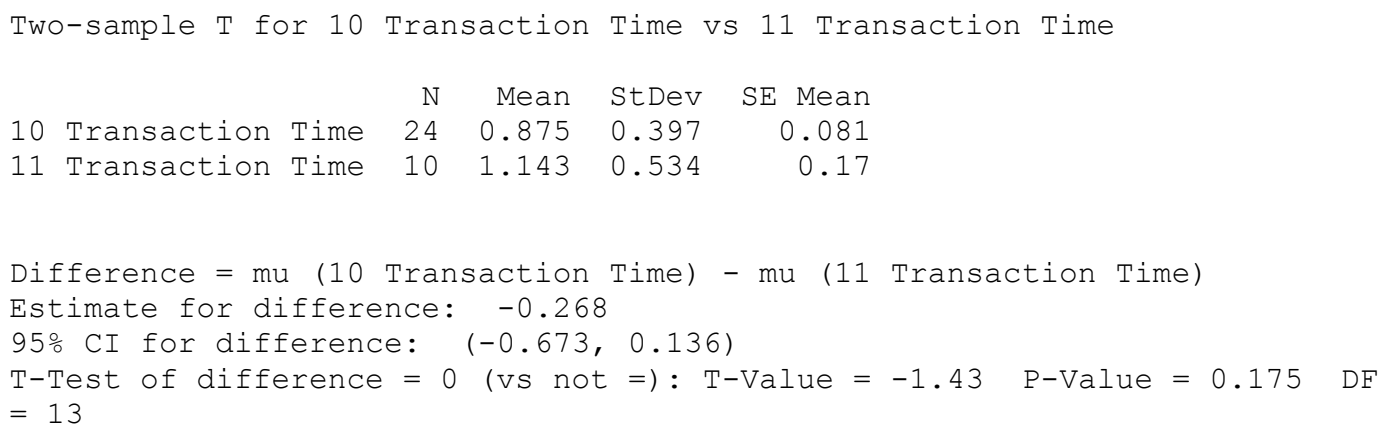

\section{Two-Sample T-Test and CI: 10 Order WT, 11 Order WT}

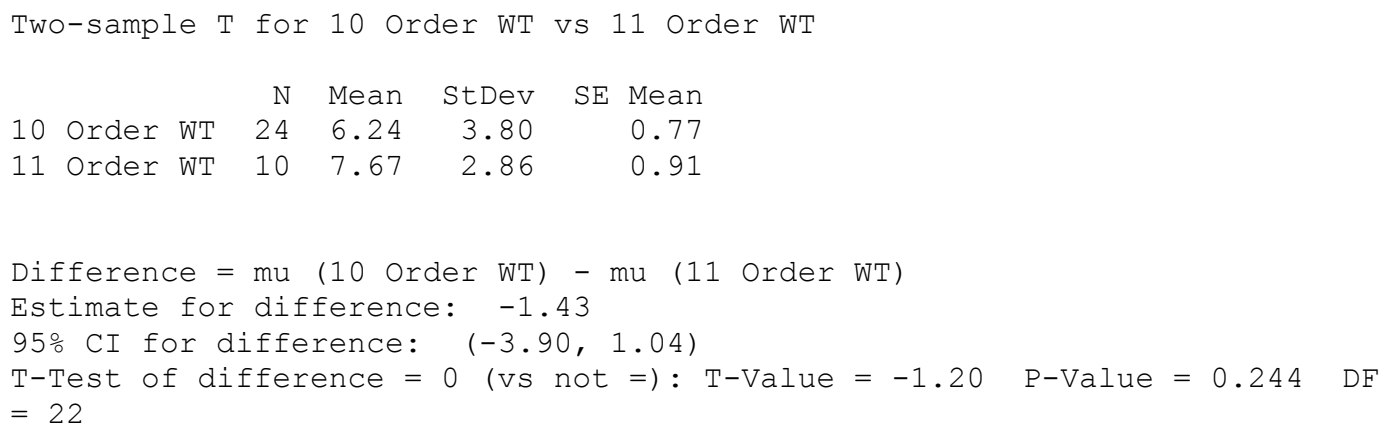




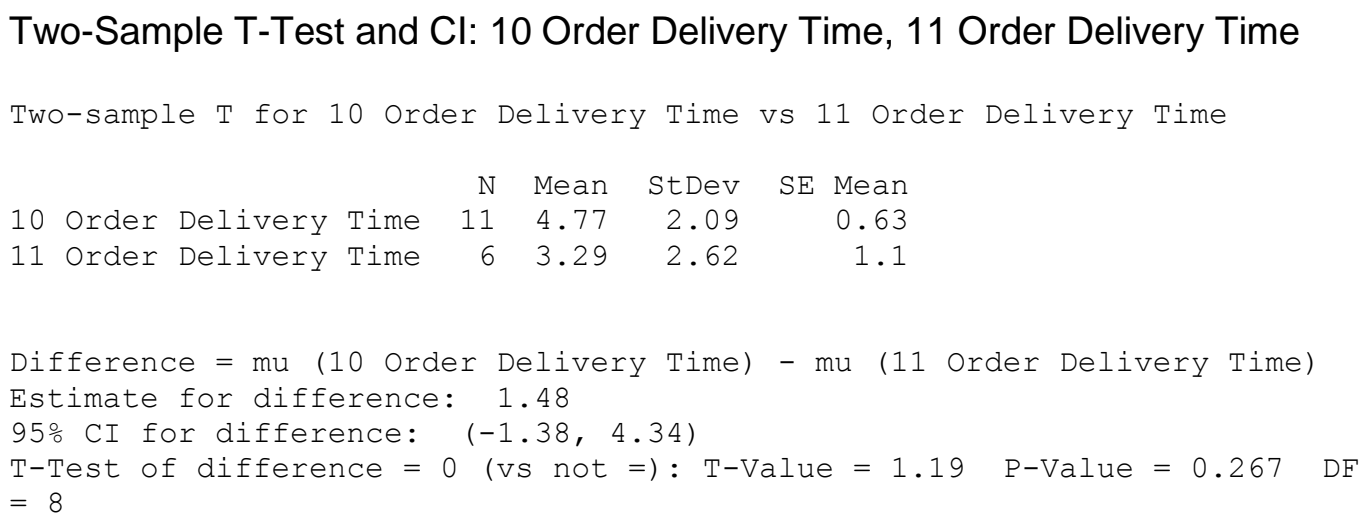

\section{Two-Sample T-Test and CI: 10 Complete Order Fulfil, 11 Complete Order Fulfil}

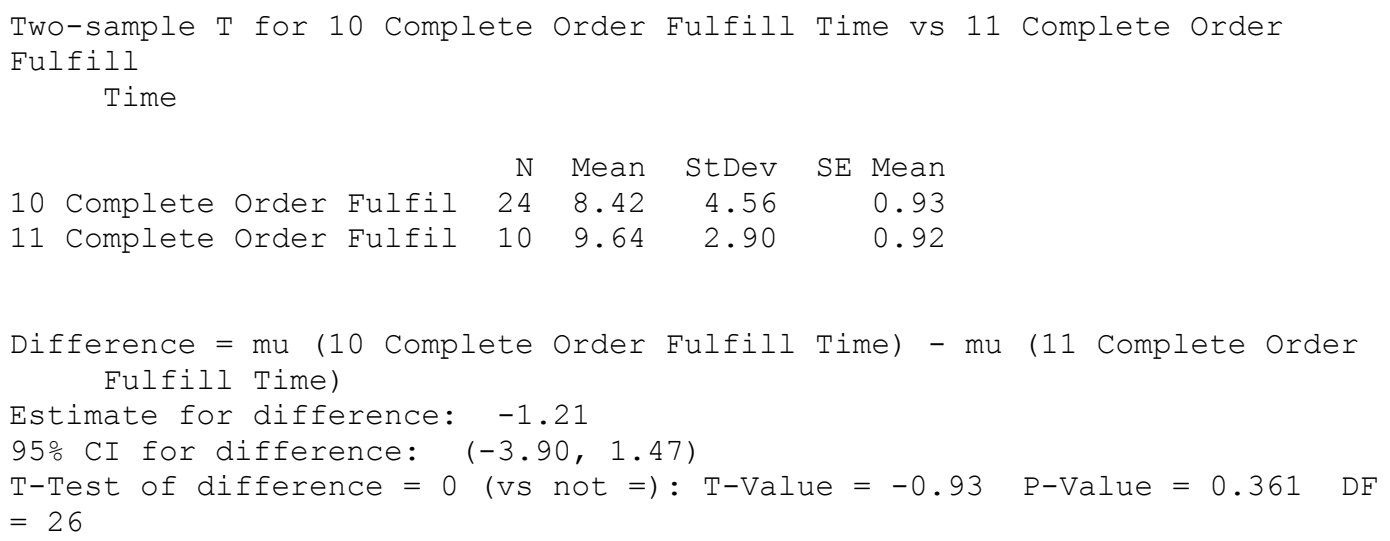

\section{Two-Sample T-Test and Cl: 10 Total Service Time, 11 Total Service Time}

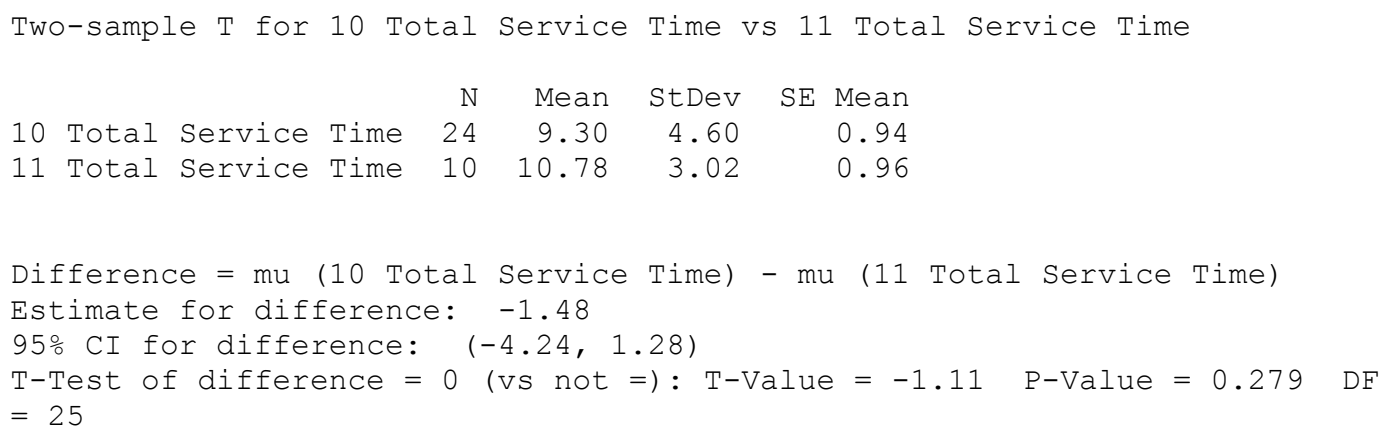




\section{Correlation Values Matrix}

\begin{tabular}{|r|r|r|r|r|r|r|}
\hline & \multicolumn{1}{|l|}{ Tangibles } & Reliability & Responsiveness & Assurance & \multicolumn{1}{l|}{$\begin{array}{l}\text { Overall P } \\
\text { Average }\end{array}$} \\
\hline Tangibles & 1.0000 & 0.3002 & 0.0664 & -0.0529 & 0.1775 & 0.4332 \\
\hline Reliability & 0.3002 & 1.0000 & 0.2528 & 0.1751 & 0.6789 & 0.8516 \\
\hline Responsiveness & 0.0664 & 0.2528 & 1.0000 & 0.0536 & 0.2009 & 0.5106 \\
\hline Assurance & -0.0529 & 0.1751 & 0.0536 & 1.0000 & 0.0444 & 0.3840 \\
\hline Empathy & 0.1775 & 0.6789 & 0.2009 & 0.0444 & 1.0000 & 0.7634 \\
\hline Overall P Average & 0.4332 & 0.8516 & 0.5106 & 0.3840 & 0.7634 & 1.0000 \\
\hline Queue WT & -0.3084 & -0.1335 & -0.1904 & 0.0974 & -0.1786 & -0.2235 \\
\hline Transaction Time & -0.2432 & 0.2503 & 0.0011 & 0.2299 & 0.1003 & 0.1400 \\
\hline Order WT & -0.3781 & -0.0797 & -0.1653 & 0.0868 & -0.1472 & -0.2015 \\
\hline Order Delivery Time & 0.0588 & 0.1170 & 0.2195 & -0.3063 & 0.0986 & 0.1054 \\
\hline Complete Order Fulfillment Time & -0.3535 & -0.0564 & -0.1937 & 0.1465 & -0.0892 & -0.1553 \\
\hline Total Service Time & -0.3748 & -0.0342 & -0.1919 & 0.1678 & -0.0885 & -0.1454 \\
\hline
\end{tabular}

\begin{tabular}{|c|c|c|c|c|c|c|}
\hline & Queue WT & Transaction Time & Order WT & $\begin{array}{l}\text { Order Delivery } \\
\text { Time }\end{array}$ & $\begin{array}{l}\text { Complete Order } \\
\text { Fulfillment Time }\end{array}$ & \begin{tabular}{|l} 
Total Service \\
Time
\end{tabular} \\
\hline Tangibles & -0.3084 & -0.2432 & -0.3781 & 0.0588 & -0.3535 & -0.3748 \\
\hline Reliability & -0.1335 & 0.2503 & -0.0797 & 0.1170 & -0.0564 & -0.0342 \\
\hline Responsiveness & -0.1904 & 0.0011 & -0.1653 & 0.2195 & -0.1937 & -0.1919 \\
\hline Assurance & 0.0974 & 0.2299 & 0.0868 & -0.3063 & 0.1465 & 0.1678 \\
\hline Empathy & -0.1786 & 0.1003 & -0.1472 & 0.0986 & -0.0892 & -0.0885 \\
\hline Overall P Average & -0.2235 & 0.1400 & -0.2015 & 0.1054 & -0.1553 & -0.1454 \\
\hline Queue WT & 1.0000 & 0.0707 & 0.9394 & -0.2708 & 0.7614 & 0.7579 \\
\hline Transaction Time & 0.0707 & 1.0000 & 0.0379 & 0.0070 & 0.0865 & 0.1887 \\
\hline Order WT & 0.9394 & 0.0379 & 1.0000 & -0.3065 & 0.7647 & 0.7604 \\
\hline Order Delivery Time & -0.2708 & 0.0070 & -0.3065 & 1.0000 & 0.3710 & 0.3771 \\
\hline Complete Order Fulfillment Time & 0.7614 & 0.0865 & 0.7647 & 0.3710 & 1.0000 & 0.9943 \\
\hline Total Service Time & 0.7579 & 0.1887 & 0.7604 & 0.3771 & 0.9943 & 1.0000 \\
\hline
\end{tabular}

\section{Correlation P-Values Matrix}

\begin{tabular}{|r|r|r|r|r|r|r|}
\hline & Tangibles & Reliability & Responsiveness & Assurance & Empathy & $\begin{array}{l}\text { Overall P } \\
\text { Average }\end{array}$ \\
\hline Tangibles & - & - & - & - & - & - \\
\hline Reliability & 0.085 & - & - & - & - & - \\
\hline Responsiveness & 0.709 & 0.149 & - & - & - & - \\
\hline Assurance & 0.767 & 0.322 & 0.763 & - & - & - \\
\hline Empathy & 0.315 & 0.000 & 0.255 & 0.803 & - & - \\
\hline Overall P Average & 0.010 & 0.000 & 0.002 & 0.025 & 0.000 & - \\
\hline Queue WT & 0.076 & 0.452 & 0.281 & 0.584 & 0.312 & 0.204 \\
\hline Transaction Time & 0.166 & 0.153 & 0.995 & 0.191 & 0.572 & 0.430 \\
\hline Order WT & 0.027 & 0.654 & 0.350 & 0.626 & 0.406 & 0.253 \\
\hline Order Delivery Time & 0.823 & 0.655 & 0.397 & 0.232 & & 0.707 \\
\hline Complete Order Fulfillment Time & 0.040 & 0.751 & 0.272 & 0.408 & 0.687 \\
\hline
\end{tabular}

\begin{tabular}{|c|c|c|c|c|c|c|}
\hline & Queue WT & Transaction Time & Order WT & \begin{tabular}{|l|} 
Order Delivery \\
Time
\end{tabular} & \begin{tabular}{|l|} 
Complete Order \\
Fulfillment Time
\end{tabular} & \begin{tabular}{|l} 
Total Service \\
Time
\end{tabular} \\
\hline Tangibles & - & \begin{tabular}{|l|l|}
- & \\
\end{tabular} & - & - & - & \\
\hline Reliability & - & - & - & - & - & - \\
\hline Responsiveness & - & - & - & - & - & - \\
\hline Assurance & - & - & - & - & - & - \\
\hline Empathy & - & - & - & - & - & - \\
\hline Overall P Average & - & - & - & - & - & - \\
\hline Queue WT & - & & - & - & - & - \\
\hline Transaction Time & 0.691 & - & - & - & - & - \\
\hline Order WT & 0.000 & 0.832 & - & - & - & - \\
\hline Order Delivery Time & 0.293 & 0.979 & 0.231 & - & - & - \\
\hline Complete Order Fulfillment Time & 0.000 & 0.627 & 0.000 & 0.143 & - & - \\
\hline Total Service Time & 0.000 & 0.285 & 0.000 & 0.136 & 0.000 & - \\
\hline
\end{tabular}




\section{Regression Analysis Minitab Outputs}

\section{Regression Analysis: Tangibles - P versus Order WT}

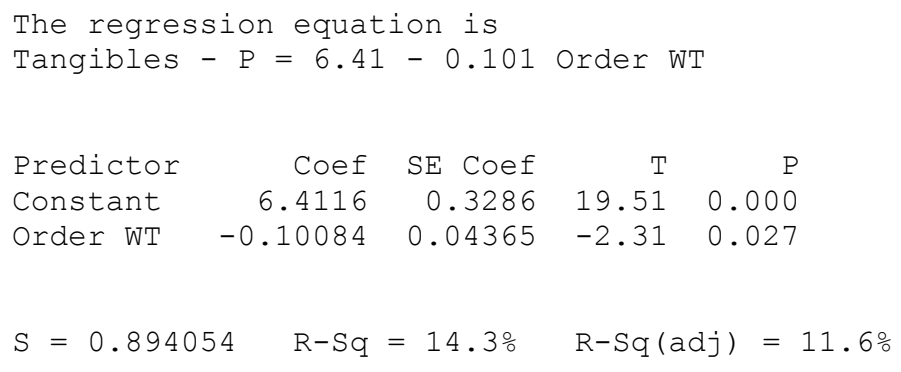

$\begin{array}{lrrrrr}\text { Source } & \text { DF } & \text { SS } & \text { MS } & \text { F } & \text { P } \\ \text { Regression } & 1 & 4.2653 & 4.2653 & 5.34 & 0.027 \\ \text { Residual Error } & 32 & 25.5786 & 0.7993 & & \\ \text { Total } & 33 & 29.8440 & & & \end{array}$

Unusual Observations

\begin{tabular}{rrrrrrr}
\multicolumn{7}{c}{ Tangibles } \\
Obs & Order WT & $-\mathrm{P}$ & Fit & SE Fit & Residual & St Resid \\
14 & 14.7 & 4.667 & 4.933 & 0.382 & -0.266 & $-0.33 \mathrm{X}$ \\
16 & 12.3 & 3.000 & 5.168 & 0.291 & -2.168 & $-2.56 \mathrm{R}$
\end{tabular}

$\mathrm{R}$ denotes an observation with a large standardized residual.

$\mathrm{X}$ denotes an observation whose $\mathrm{X}$ value gives it large leverage.

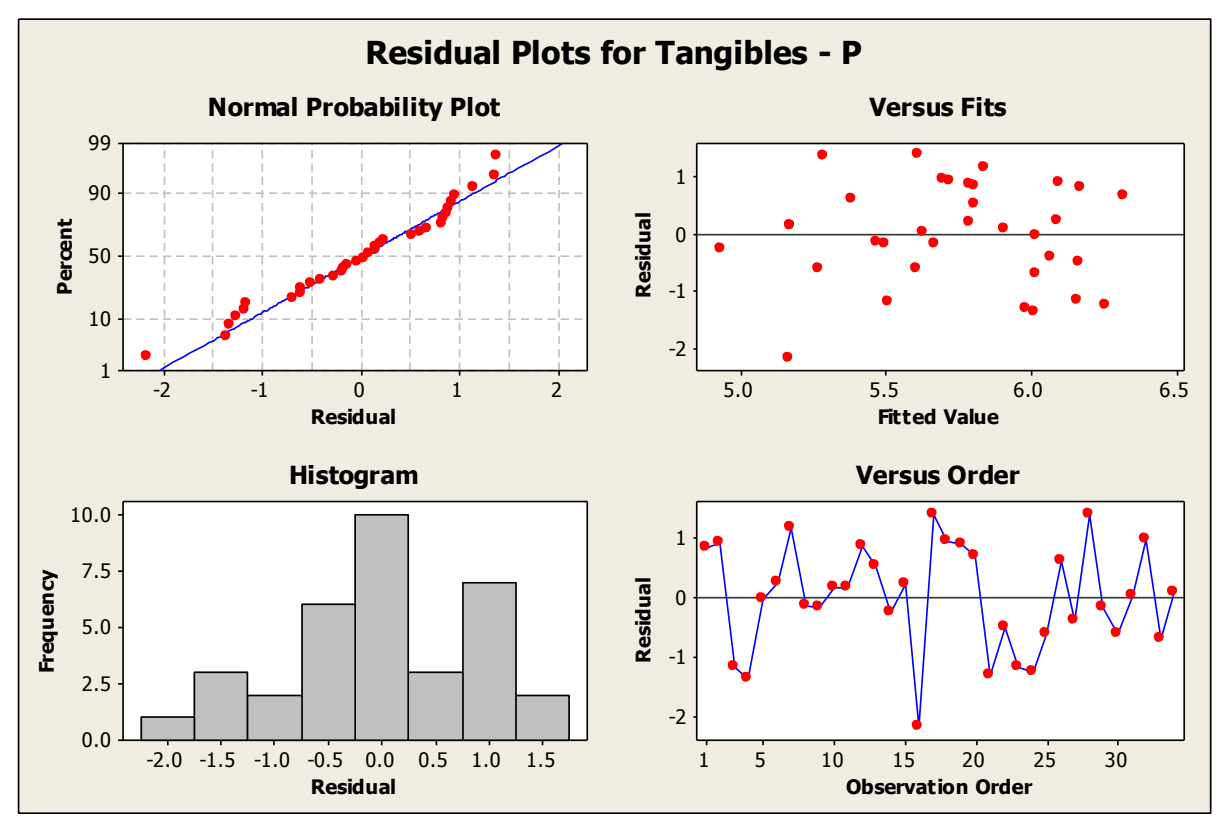


Polynomial Regression Analysis: Tangibles - P versus Order WT
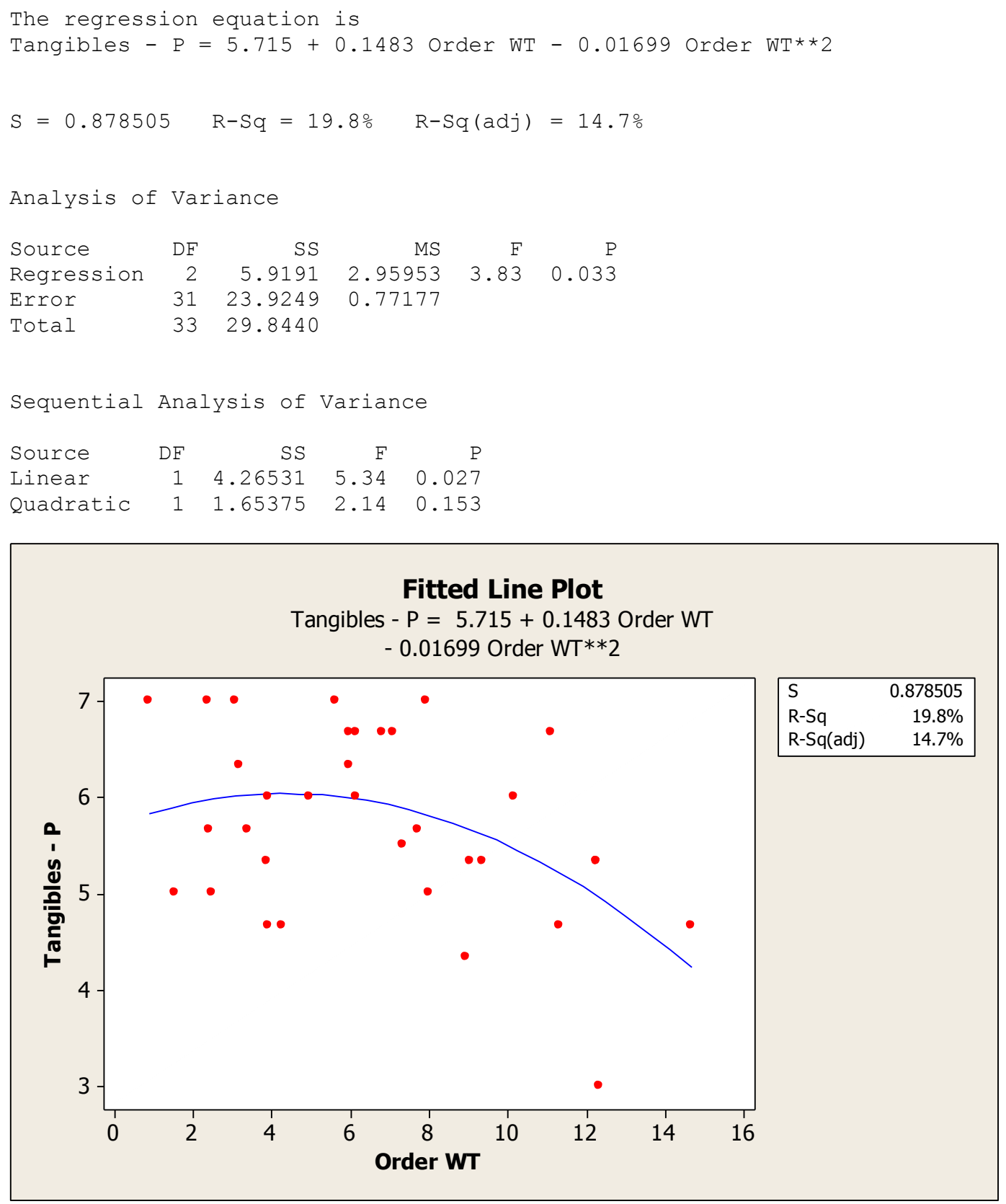
Regression Analysis: Assurance - P versus $\ln ($ Order Delivery Time)

The regression equation is

Assurance $-\mathrm{P}=6.88-0.592$ ln (Order Delivery Time)

17 cases used, 17 cases contain missing values

$\begin{array}{lrrrr}\text { Predictor } & \text { Coef } & \text { SE Coef } & \text { T } & \text { P } \\ \text { Constant } & 6.8835 & 0.6718 & 10.25 & 0.000 \\ \text { ln(Order Delivery Time) } & -0.5923 & 0.4753 & -1.25 & 0.232 \\ & & & & \\ S=1.12001 \quad \text { R-Sq }=9.4 \% & \text { R-Sq (adj) }=3.3 \%\end{array}$

Analysis of Variance

$\begin{array}{lrrrrr}\text { Source } & \text { DF } & \text { SS } & \text { MS } & \text { F } & \text { P } \\ \text { Regression } & 1 & 1.948 & 1.948 & 1.55 & 0.232 \\ \text { Residual Error } & 15 & 18.816 & 1.254 & & \\ \text { Total } & 16 & 20.765 & & & \end{array}$

Total $16 \quad 20.765$

Unusual Observations

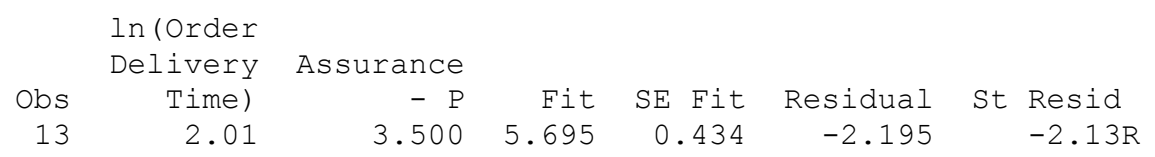

R denotes an observation with a large standardized residual.

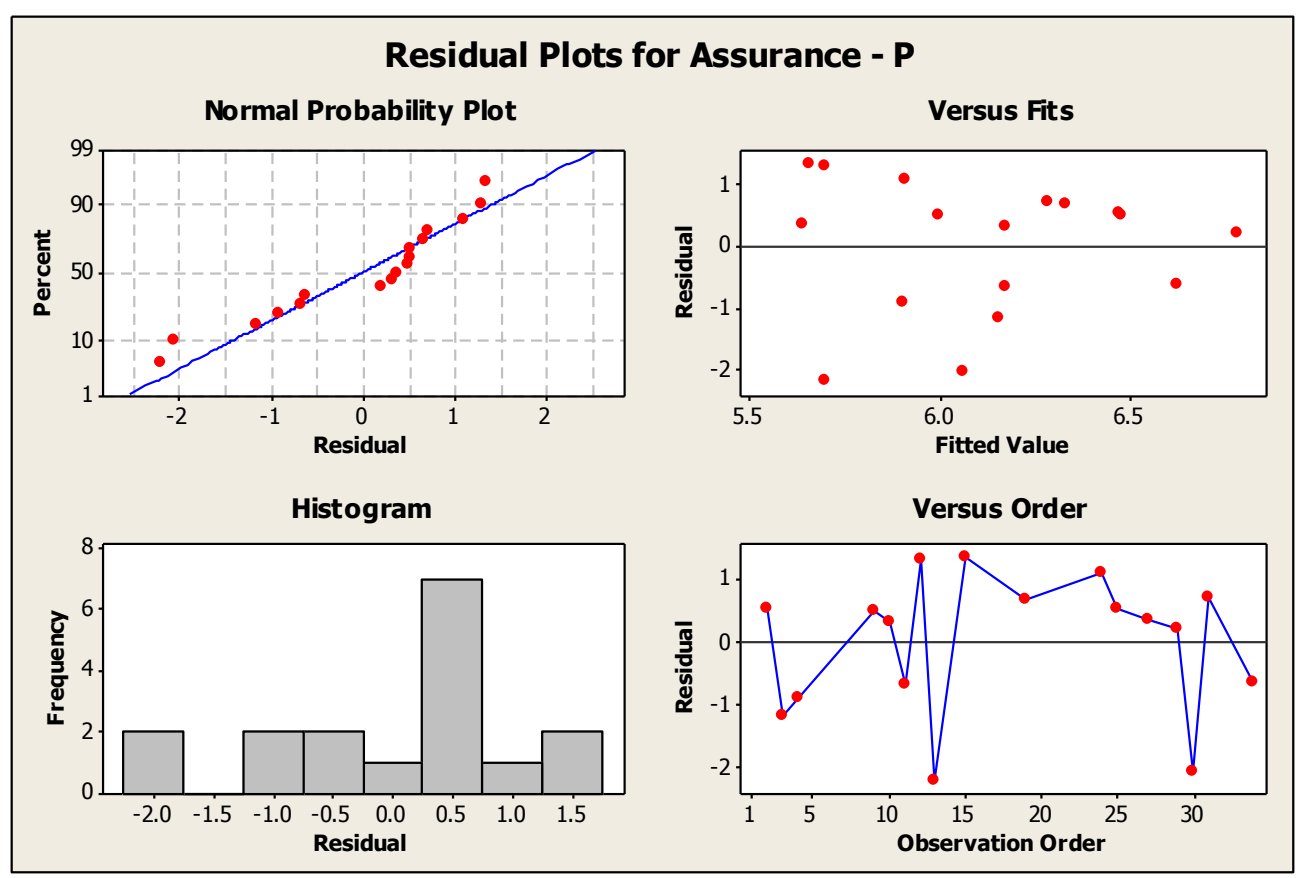




\title{
Appendix B: Study Documents
}

\author{
Informed Consent Form \\ INFORMED CONSENT TO PARTICIPATE IN A RESEARCH PROJECT, \\ "Investigating the Relationship Between Restaurant Operations Efficiency and \\ Service Quality"
}

A research project on restaurant efficiency and service quality is being conducted by Monica Reinwald, a student_in the Department of Industrial and Manufacturing Engineering at Cal Poly, San Luis Obispo, under the supervision of Dr. Liz Schlemer. The purpose of the study is to determine if there is a definable relationship between operations efficiency and service quality in the restaurant industry.

You are being asked to take part in this study by completing the attached questionnaire. Your participation will take approximately 2-3 minutes. Please be aware that you are not required to participate in this research and you may discontinue your participation at any time without penalty. You may also omit any items on the questionnaire you prefer not to answer. Your responses will be provided anonymously to protect your privacy.

There are no risks associated with participation in this study. In addition to contributing to our understanding of the relationship between restaurant operations efficiency and perceived service quality, you will be given a $\$ 2$ credit towards your next restaurant purchase.

If you have questions regarding this study or would like to learn the results of this study, please feel free to contact Monica Reinwald at mreinwal@calpoly.edu. If you have concerns regarding the manner in which the study is conducted, you may contact Dr. Steve Davis, Chair of the Cal Poly Human Subjects Committee, at (805) 756-2754, sdavis@calpoly.edu, or Dr. Dean Wendt, Interim Dean of Research, at (805) 756-1508,dwendt@calpoly.edu.

If you agree to voluntarily participate in this research project as described, please indicate your agreement by completing and returning the attached questionnaire. Please retain this consent cover form for your reference, and thank you for your participation in this research. 
Directions: This survey deals with your opinions of restaurant services. Please show the extent to which you think firms offering restaurant services should possess the features described by each statement. Do this by picking one of the seven numbers next to each statement. If you strongly agree that these firms should possess a feature, circle the number 7 . If you strongly disagree that these firms should possess a feature, circle 1 . If your feelings are not strong, circle one of the numbers in the middle. There ace og rightor wrong answers - all we are interested in is a number that best shows your expectations about firms offering restaurant services.

\begin{tabular}{|c|c|c|c|c|c|c|c|}
\hline \multirow{2}{*}{$\begin{array}{l}\text { Regarding Firms Offering Restaurant Services } \\
\text { They should have up-to-date equipment. }\end{array}$} & \multicolumn{2}{|c|}{ Iy Disagree } & \multicolumn{3}{|c|}{ Neutral } & \multicolumn{2}{|c|}{ Strongly Agree } \\
\hline & 1 & 2 & 3 & 4 & 5 & 6 & 7 \\
\hline Their physical facilities should be visually appealing. & 1 & 2 & 3 & 4 & 5 & 6 & 7 \\
\hline Their employees should be well dressed and appear neat. & 1 & 2 & 3 & 4 & 5 & 6 & 7 \\
\hline $\begin{array}{l}\text { When these firms promise to do something by a certain time, } \\
\text { they should do so. }\end{array}$ & 1 & 2 & 3 & 4 & 5 & 6 & 7 \\
\hline $\begin{array}{l}\text { When customers have problems, these firms should be } \\
\text { sympathetic and reassuring. }\end{array}$ & 1 & 2 & 3 & 4 & 5 & 6 & 7 \\
\hline These firms should be dependable. & 1 & 2 & 3 & 4 & 5 & 6 & 7 \\
\hline $\begin{array}{l}\text { They should provide their services at the time they promise to } \\
\text { do so. }\end{array}$ & 1 & 2 & 3 & 4 & 5 & 6 & 7 \\
\hline $\begin{array}{l}\text { It is not realistic for customers to expect prompt service from } \\
\text { employees of these firms. }\end{array}$ & 1 & 2 & 3 & 4 & 5 & 6 & 7 \\
\hline $\begin{array}{l}\text { Their employees don't always have to be willing to help } \\
\text { customers. }\end{array}$ & 1 & 2 & 3 & 4 & 5 & 6 & 7 \\
\hline $\begin{array}{l}\text { It is okay if they are too busy to respond to customer requests } \\
\text { promptly. }\end{array}$ & 1 & 2 & 3 & 4 & 5 & 6 & 7 \\
\hline $\begin{array}{l}\text { Customers should be able to feel safe in their transactions } \\
\text { with these firms' employees. }\end{array}$ & 1 & 2 & 3 & 4 & 5 & 6 & 7 \\
\hline Their employees should be polite. & 1 & 2 & 3 & 4 & 5 & 6 & 7 \\
\hline $\begin{array}{l}\text { These firms should not be expected to give customers } \\
\text { individual attention. }\end{array}$ & 1 & 2 & 3 & 4 & 5 & 6 & 7 \\
\hline $\begin{array}{l}\text { Employees of these firms cannot be expected to give } \\
\text { customers personal attention. }\end{array}$ & 1 & 2 & 3 & 4 & 5 & 6 & 7 \\
\hline $\begin{array}{l}\text { It is unrealistic to expect these firms to have their customers' } \\
\text { best interests at heart. }\end{array}$ & 1 & 2 & 3 & 4 & 5 & 6 & 7 \\
\hline $\begin{array}{l}\text { They shouldn't be expected to have operating hours } \\
\text { convenient to all their customers. }\end{array}$ & 1 & 2 & 3 & 4 & 5 & 6 & 7 \\
\hline
\end{tabular}

Please continue survey on back of page. 
Directions: The following set of statements relate to your fee lings about . For each statement, please show the extent to which you believe has the feature described by the statement. Once again, circling a 7 means that you strongly agree that has that feature, and circling a 1 means that you strongly disagree. You may circle any of the numbers in the middle that show how strong your feelings are. There are no right or wrong answers - all we are interested in is a number that best shows your perceptions about

Regarding

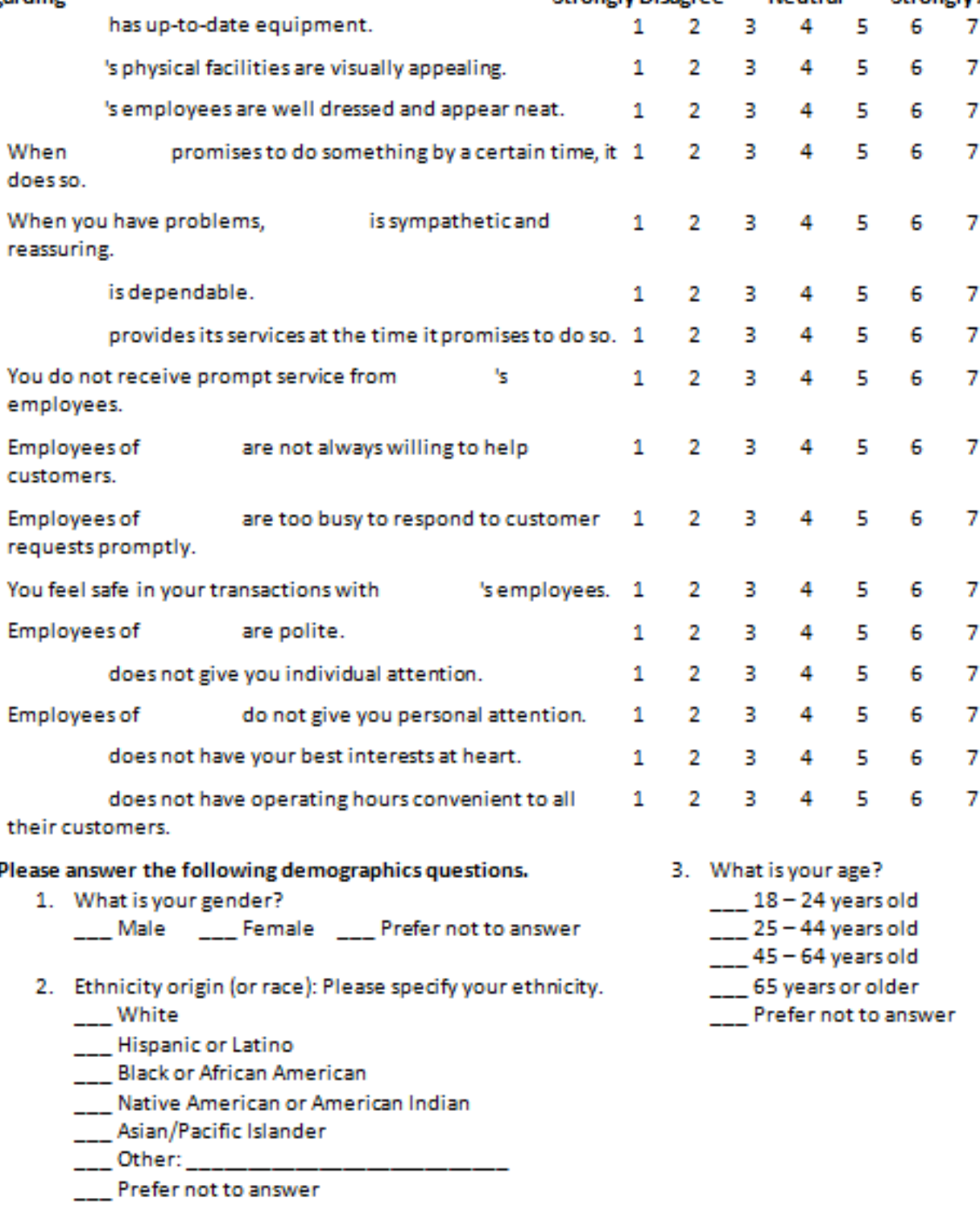

Thank you for your participation! 
Data Collection Sheet

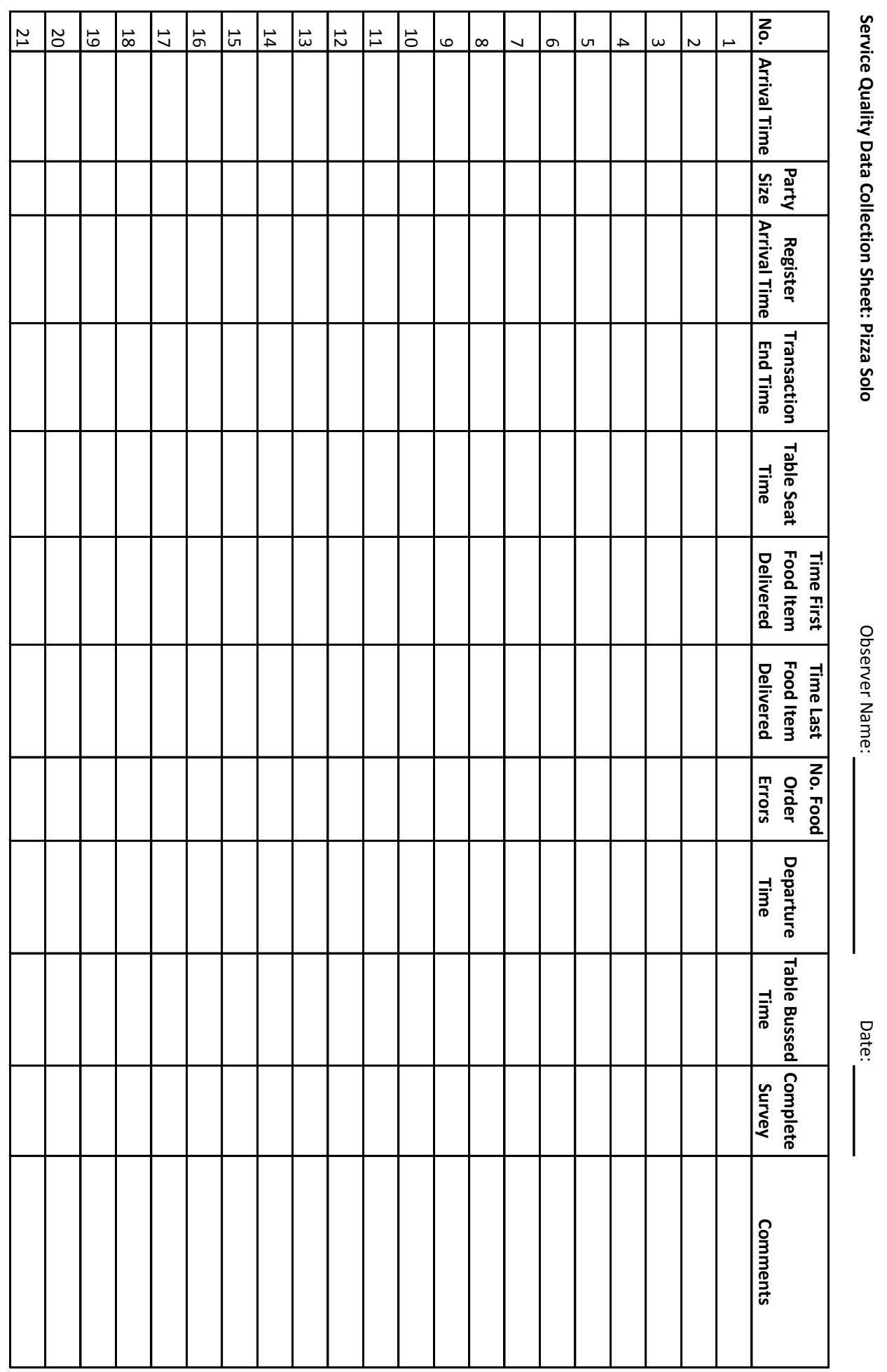

